\title{
Glutamate Receptor Subtypes Mediating Synaptic Activation of Prefrontal Cortex Neurons: Relevance for Schizophrenia
}

\author{
Diana C. Rotaru, ${ }^{1}$ Hiroki Yoshino, ${ }^{1}$ David A. Lewis, ${ }^{1,2}$ G. Bard Ermentrout, ${ }^{3}$ and Guillermo Gonzalez-Burgos ${ }^{1}$ \\ ${ }^{1}$ Translational Neuroscience Program, Department of Psychiatry, University of Pittsburgh School of Medicine, Pittsburgh, Pennsylvania 15261, \\ and Departments of ${ }^{2}$ Neuroscience and ${ }^{3}$ Mathematics, University of Pittsburgh, Pittsburgh, Pennsylvania 15260
}

\begin{abstract}
Schizophrenia may involve hypofunction of NMDA receptor (NMDAR)-mediated signaling, and alterations in parvalbumin-positive fast-spiking (FS) GABA neurons that may cause abnormal gamma oscillations. It was recently hypothesized that prefrontal cortex (PFC) FS neuron activity is highly dependent on NMDAR activation and that, consequently, FS neuron dysfunction in schizophrenia is secondary to NMDAR hypofunction. However, NMDARs are abundant in synapses onto PFC pyramidal neurons; thus, a key question is whether FS neuron or pyramidal cell activation is more dependent on NMDARs. We examined the AMPAR and NMDAR contribution to synaptic activation of FS neurons and pyramidal cells in the PFC of adult mice. In FS neurons, EPSCs had fast decay and weak NMDAR contribution, whereas in pyramidal cells, EPSCs were significantly prolonged by NMDAR-mediated currents. Moreover, the AMPAR/NMDAR EPSC ratio was higher in FS cells. NMDAR antagonists decreased EPSPs and EPSP-spike coupling more strongly in pyramidal cells than in FS neurons, showing that FS neuron activation is less NMDAR dependent than pyramidal cell excitation. The precise EPSP-spike coupling produced by fast-decaying EPSCs in FS cells may be important for network mechanisms of gamma oscillations based on feedback inhibition. To test this possibility, we used simulations in a computational network of reciprocally connected FS neurons and pyramidal cells and found that brief AMPAR-mediated FS neuron activation is crucial to synchronize, via feedback inhibition, pyramidal cells in the gamma frequency band. Our results raise interesting questions about the mechanisms that might link NMDAR hypofunction to alterations of FS neurons in schizophrenia.
\end{abstract}

\section{Introduction}

Hypofunction of NMDA receptor (NMDAR)-mediated signaling has been implicated in the disease process of schizophrenia because NMDAR antagonist administration mimics core symptoms of the illness, including cognitive deficits (Javitt and Zukin, 1991; Javitt, 2009). However, identifying potential sites of NMDAR hypofunction has proved elusive, given the modest and often contradictory changes in NMDARs observed in postmortem studies of schizophrenia (Kristiansen et al., 2007), and the challenges of determining the sites where NMDAR antagonists act to mimic schizophrenia symptoms.

Schizophrenia may involve dysfunction of prefrontal cortex (PFC) inhibitory GABA neurons, including the parvalbumin (PV)-containing cells (Lewis et al., 2005), whose activity is essential to generate gamma oscillations (Cardin et al., 2009; Sohal et al., 2009). PV neuron alterations may underlie the impairment of

Received April 17, 2010; revised Aug. 11, 2010; accepted 0ct. 23, 2010.

This work was funded by National Institutes of Health Grant MH084053. D.A.L. currently receives investigatorinitiated research support from the BMS Foundation, Bristol-Myers Squibb, Curidium, and Pfizer and in 2007-2009 served as a consultant to AstraZeneca, BioLine RX, Bristol-Myers Squibb, Hoffman-Roche, Lilly, Merck, Neurogen, and SK Life Science. We are grateful to Olga Krimer for excellent assistance with histological techniques and 3D neuron reconstruction. We also thank Dr. Diego Pafundo for providing data from recordings from $G 42$ mice.

Correspondence should be addressed to Guillermo Gonzalez-Burgos, Translational Neuroscience Program, Department of Psychiatry, University of Pittsburgh School of Medicine, Room W1651, Biomedical Science Tower, 200 Lothrop Street, Pittsburgh, PA 15261. E-mail: gburgos@pitt.edu.

D. C. Rotaru's present address: Department of Molecular and Cellular Neurobiology, Vrije University, 1081 HV Amsterdam, Netherlands.

DOI:10.1523/JNEUROSCI.1970-10.2011

Copyright $\odot 2011$ the authors $\quad 0270-6474 / 11 / 310142-15 \$ 15.00 / 0$ gamma oscillations and thus cognitive dysfunction in schizophrenia (Cho et al., 2006), since gamma band synchrony is important for cognition (Fries, 2009).

Recent studies proposed that alterations of PV neurons in schizophrenia are secondary to NMDAR hypofunction. For example, NMDAR antagonists decrease mRNA expression for PV and the GABA-synthesis enzyme GAD67 (Cochran et al., 2003; Behrens et al., 2007), resembling the decrease of PV and GAD67 in schizophrenia (Lewis et al., 2005). Interestingly, systemic administration of NMDAR antagonists increases PFC pyramidal cell firing, apparently by producing disinhibition (Homayoun and Moghaddam, 2007). Moreover, NMDAR antagonists decrease disynaptic inhibition onto hippocampal pyramidal cells (Grunze et al., 1996). Therefore NMDAR antagonists, or NMDAR hypofunction in schizophrenia, could alter PFC circuit function by disinhibiting pyramidal cells via primary effects on PV neurons (Coyle, 2004; Lewis and Moghaddam, 2006). A crucial question is therefore whether normally NMDAR-mediated currents are stronger in PV interneurons or in PFC pyramidal cells.

PV-positive neurons have unique fast-spiking (FS) electrophysiological properties (Kawaguchi and Kubota, 1997; Galarreta and Hestrin, 2002; Pawelzik et al., 2002), which are crucial for their role in gamma oscillations (Bartos et al., 2007; Mann and Paulsen, 2007; Doischer et al., 2008). Furthermore, the properties of glutamate synapses onto FS neurons are also critical, since the network mechanisms of gamma oscillations may involve recurrent excitation-inhibition between pyramidal neurons and FS cells (Hájos and Paulsen, 2009). 
FS neurons display a remarkably fast synaptic activation $(\mathrm{Hu}$ et al., 2010), which may require short-lasting EPSCs, because long-lasting EPSCs produce spikes during prolonged time windows (Fricker and Miles, 2000; Maccaferri and Dingledine, 2002). Fast synaptic activation may involve weak NMDAR contribution, because NMDAR-EPSCs typically are long-lasting (Hestrin et al., 1990; Cull-Candy and Leszkiewicz, 2004). Interestingly, in hippocampus and somatosensory cortex FS neurons actually display short-lasting EPSCs with weak NMDAR contribution (Geiger et al., 1997; Angulo et al., 1999; Lu et al., 2007; Hull et al., 2009).

In PFC circuits, the contribution of synaptic NMDARs to activation of specific populations of neurons is poorly understood. This information is important to determine what cell types could mediate NMDAR hypofunction and the possible mechanisms linking NMDAR hypofunction with gamma oscillation abnormalities in schizophrenia. Here, we examined the NMDAR contribution to synaptic activation of PFC FS neurons and pyramidal cells and the influence of AMPARs and NMDARs in the production of gamma oscillations via feedback inhibition.

\section{Materials and Methods}

\section{Slices}

Experiments were conducted in brain slices prepared from the frontal cortex of 6-week- to 4-month-old C57BL/6 mice of either sex (Charles River), using methods described previously (Rotaru et al., 2007). Animals were treated following procedures in accordance with National Institutes of Health guidelines and approved by the University of Pittsburgh's Institutional Animal Care and Use Committee. For electrophysiological recordings, slices were transferred to a recording chamber and superfused at a flow rate of $2 \mathrm{ml} / \mathrm{min}$ with artificial CSF (ACSF) containing the following (in mM): $126 \mathrm{NaCl}, 2.5 \mathrm{KCl}, 1 \mathrm{MgCl}_{2}, 2 \mathrm{CaCl}_{2}, 25$ $\mathrm{NaHCO}_{3}, 1.25 \mathrm{Na}_{2} \mathrm{HPO}_{4}$, and 10 glucose, $\mathrm{pH}$ 7.3-7.4 when gassed with carbogen $\left(95 \% \mathrm{O}_{2}\right.$ and $\left.5 \% \mathrm{CO}_{2}\right)$. Chamber temperature was adjusted to $30-32^{\circ} \mathrm{C}$. Unless specifically indicated, the standard ACSF routinely contained $10 \mu \mathrm{M}$ gabazine, to block $\mathrm{GABA}_{\mathrm{A}}$ receptor-mediated synaptic transmission.

\section{Electrophysiology}

Patch pipette, tight seal whole-cell recordings were obtained from layer 5 pyramidal cells and interneurons in the infralimbic, prelimbic, or anterior cingulate regions of the mouse medial frontal cortex, here collectively referred to as mouse PFC. Cells were visualized using Olympus or Zeiss microscopes equipped with infrared illumination and differential interference contrast videomicroscopy. Pipettes pulled from borosilicate glass had a resistance of 3-6 $\mathrm{M} \Omega$ when filled with the following solution (in mM): K-gluconate $120, \mathrm{NaCl} 10$, HEPES 10, EGTA 0.2, MgATP 4.5, NaGTP 0.3 , and Na-phosphocreatine 14 and $0.2-0.5 \%$ biocytin, and the $\mathrm{pH}$ was adjusted to 7.2-7.4 using $\mathrm{KOH}$. Recordings were obtained using Multiclamp 700 amplifiers (Molecular Devices). Signals were low-pass filtered at $4 \mathrm{kHz}$ and digitized at 10 or $20 \mathrm{kHz}$ using Power 1401 data acquisition interfaces (Cambridge Electronic Design). Data acquisition and analysis were performed using Signal 4 software (Cambridge Electronic Design).

Voltage clamp. The pipette capacitance was compensated and series resistance was continuously monitored but was not compensated. Only recordings with a stable series resistance of $<20 \mathrm{M} \Omega$ were used for analysis. NMDAR contribution to EPSCs is best estimated at positive membrane potentials, to largely relieve NMDAR channels from $\mathrm{Mg}^{2+}$ block. Good quality voltage-clamp recordings at positive potentials require using $\mathrm{Cs}^{+}$-based pipette solutions to improve voltage-clamp conditions. However, $\mathrm{Cs}^{+}$blocks $\mathrm{K}^{+}$channels and severely distorts the cells' firing properties, preventing the identification of FS neurons. Therefore, we measured the NMDAR contribution by recording in nominally $\mathrm{Mg}^{2+}$. free conditions using $\mathrm{K}^{+}$-based pipette solutions, and voltage clamping the cells near their resting membrane potential (see Figs. 2, 3). Slices were incubated before recording for $20 \mathrm{~min}$ in $\mathrm{Mg}^{2+}$-free $\mathrm{ACSF}\left(\mathrm{MgCl}_{2}\right.$ omitted), and the same $\mathrm{Mg}^{2+}$-free ACSF was used continuously during recordings.

Current clamp. Series resistance and pipette capacitance were monitored and cancelled using bridge and capacitance neutralization. To measure the cells' firing properties, incremental depolarizing current steps (500 ms duration) were injected until producing spikes repetitively. Membrane potential measurements were not corrected for liquid junction potential. In experiments estimating the NMDAR contribution to EPSPs, recordings were done in standard extracellular $\mathrm{Mg}^{2+}$ concentration (1 mM), depolarizing the cells to membrane potential values near threshold by constant current injection via the whole-cell recording pipette.

Extracellular stimulation. Synaptic inputs were stimulated using electrodes fabricated with theta-type capillary glass pulled to an open tip diameter of $\sim 3-5 \mu \mathrm{m}$ and filled with oxygenated ACSF. Silver wires inserted into the theta glass were connected to a stimulus isolation unit (World Precision Instruments) commanded by TTL pulses. Stimulation electrodes were typically placed within $100-200 \mu \mathrm{m}$ of the soma of the recorded neuron. Stimuli of $100 \mu$ s duration had current intensity adjusted $(10-100 \mu \mathrm{A})$ to produce apparently monosynaptic responses with no obvious contamination by polysynaptic events. To produce disynaptic IPSPs in the absence of monosynaptic IPSPs (see Fig. 7), horizontal inputs were stimulated placing the stimulation electrode at $>300 \mu \mathrm{m}$ lateral to the recorded neuron.

\section{Morphological analysis}

Biocytin-filled neurons were visualized using the Vectastain Elite ABC kit (Vector Laboratories) and their axonal and dendritic trees reconstructed using the Neurolucida Tracing System (Microbrightfield Bioscience) as described previously (Povysheva et al., 2008; Zaitsev et al., 2009). Typically, FS cells belong to one of two different morphological classes: chandelier neurons and the so-called basket cells (Markram et al., 2004). All the biocytin-filled FS neurons morphologically identified in this study were classified as basket cells (Fig. 1).

\section{Electrophysiology data analysis}

Neuron classification. Pyramidal cells and interneurons were identified visually before recording, and their morphology was confirmed subsequently (Fig. 1). Because the NMDAR contribution to excitatory inputs is strong in interneurons of non-FS subtypes (Lu et al., 2007; Wang and Gao, 2009), we only included interneurons unambiguously classified as FS. To distinguish FS cells from non-FS interneurons, depolarizing current steps were used to analyze the firing response of each interneuron. Single spike properties were determined on spikes elicited by near threshold current injection. Spike-frequency adaptation was quantified by the ratio between the last and first interspike intervals in spike trains evoked by $500 \mathrm{~ms}$ depolarizing steps. Cells were classified as FS if they had the following: (1) narrow spikes (duration at half peak amplitude $\leq 0.6 \mathrm{~ms}$ ); (2) large afterhyperpolarizing potentials (amplitude $\geq 15 \mathrm{mV}$ ); and (3) absence of significant spike-frequency adaptation (adaptation ratio $\leq 1.2$ ). These criteria may exclude some FS neurons, but ensure focusing on FS cells (Fig. 1 B). As we (Zaitsev et al., 2005, 2009; Povysheva et al., 2008) and other laboratories (Kawaguchi and Kubota, 1997; Galarreta and Hestrin, 2002; Pawelzik et al., 2002) demonstrated previously, FS electrical properties are highly correlated with PV expression. To verify that our criteria to classify interneurons as FS and to exclude non-FS were appropriate, we measured the parameters described above in recordings from green fluorescent protein-positive neurons in slices from G42 mice (see supplemental Table 1, available at www. jneurosci.org as supplemental material), a mouse strain in which the fluorescent protein is expressed exclusively in PV-positive-FS neurons (Chattopadhyaya et al., 2004).

EPSC data analysis. Spontaneous EPSCs (sEPSCs) recorded at -70 $\mathrm{mV}$ in nominal $\mathrm{Mg}^{2+}$ free conditions were detected using Mini analysis software (Synaptosoft). For each cell, at least 200 events detected in control conditions or in the presence of AP5 were averaged. The peak amplitude of the average sEPSC was measured relative to the baseline current. The decay kinetics was quantified by fitting a double 
exponential function and computing a weighted decay time constant $\left(\tau_{w}\right)$ as follows:

$$
\tau_{w}=\frac{A_{\text {slow }} \times \tau_{\text {slow }}+A_{\text {fast }} \times \tau_{\text {fast }}}{A_{\text {slow }} \times A_{\text {fast }}},
$$

where $A_{\text {slow }}, A_{\text {fast }}, \tau_{\text {slow, }}$, and $\tau_{\text {fast }}$ are the amplitudes and decay time constants of slow and fast IPSC decay components. To estimate the AMPA/NMDA sEPSC charge ratio, first we obtained, by waveform subtraction, the NMDAmediated sEPSC as follows: NMDA waveform $=$ control waveform - AMPA waveform, where the AMPA waveform was that recorded in the presence of the NMDA antagonist AP5. Charge was estimated by the area under the sEPSC waveform curve.

To analyze EPSCs evoked by extracellular stimulation (eEPSCs), at least 20 responses were averaged from recordings in control conditions or in the presence of the AMPAR antagonist CNQX. Analysis of amplitude, decay kinetics, and charge of the average eEPSC was done as for the sEPSCs. To estimate the AMPA/ NMDA eEPSC charge ratio, first the AMPAmediated eEPSC was obtained by waveform subtraction as follows: AMPA waveform = control waveform - NMDA waveform, where the NMDA waveform was that recorded in the presence of the AMPAR antagonist CNQX.

EPSP data analysis. Spontaneous EPSPs (sEPSPs) recorded in control conditions or in the presence of AP5 at two different membrane potentials (100-200 events at approximately $-80 \mathrm{mV}$ and at least 70 events near threshold) were detected using Mini analysis software (Synaptosoft). An average sEPSP was obtained for each condition (control and AP5, hyperpolarized and depolarized). To analyze EPSPs evoked by focal extracellular stimulation (eEPSPs), 20 consecutive eEPSPs recorded at each membrane potential were averaged (control and AP5). At depolarized potentials, sEPSP and eEPSP decay were not well fit by exponential functions; thus, the effects of depolarization and NMDAR activation were quantified by measuring changes in the EPSP area, computing a ratio between the EPSP area at depolarized and hyperpolarized potentials (or D/H EPSP area ratio, obtained in control conditions and in the presence of AP5). The D/H ratio compensates for the within-cell variability in the depolarization effects on EPSP area, which, especially in pyramidal cells, vary markedly depending on EPSP size and the subthreshold depolarized potential at which each particular neuron was recorded (Stuart and Sakmann, 1995; González-Burgos and Barrionuevo, 2001; Rotaru et al., 2007).

To quantify the magnitude of EPSP summation during stimulus trains, first we obtained an average of all the recorded EPSP trains that remained subthreshold (see Figs. 5, 6). In the average traces, we measured the amplitude of the first $\left(\mathrm{EPSP}_{1}\right)$ and fifth $\left(\mathrm{EPSP}_{5}\right)$ EPSPs, relative to the membrane potential measured just prior $(10 \mathrm{~ms})$ to EPSP $_{1}$. Summation was estimated by computing the $\mathrm{EPSP}_{5} / \mathrm{EPSP}_{1}$ ratio for each neuron in each condition.

Spike probability during EPSP-spike coupling. The probability of eliciting spikes by EPSP trains at depolarized potentials was estimated as the proportion of EPSP trains with spikes (independent of the number of spikes per train) out of the total number of trains recorded. Typically, at least 20 consecutive trains were used to estimate the spike probability in control conditions or in the presence of AP5. Spike probability was quantified similarly when testing the effects of the $\mathrm{GABA}_{\mathrm{A}}$ receptor antagonist gabazine $(2 \mu \mathrm{M})$ or of the use-dependent NMDA channel blocker MK801 $(10 \mu \mathrm{M})$.
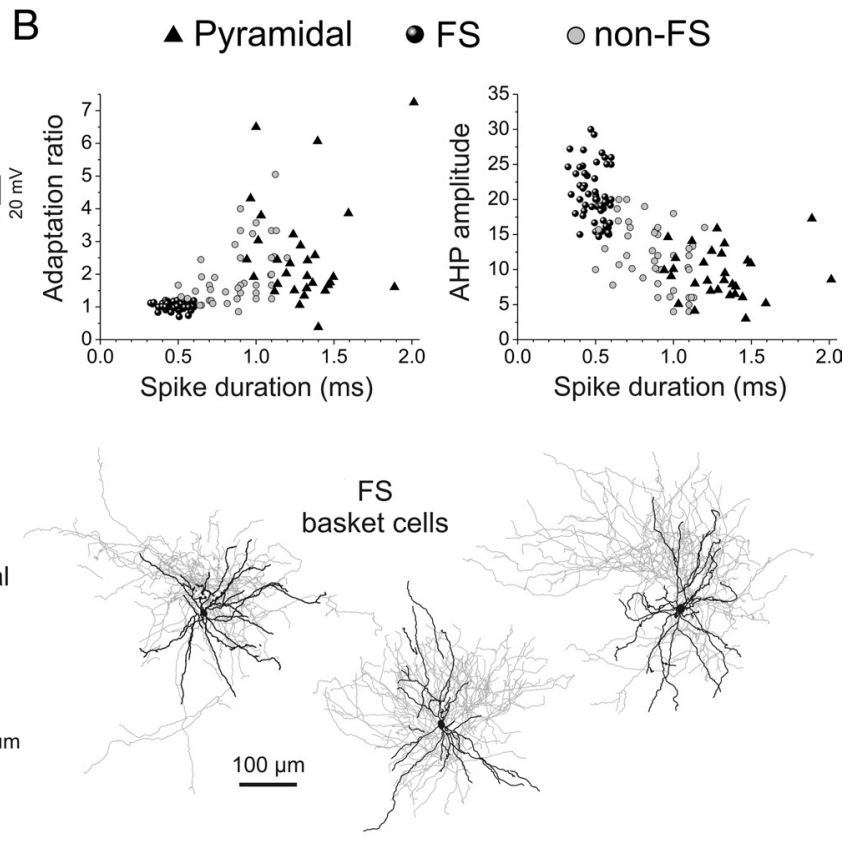

Figure 1. PFC pyramidal cells and FS interneurons were identified based on their firing pattern and morphological properties. , were found in this data sample). Axons shown in gray, dendrites in black.

\section{Chemicals}

Biocytin was obtained from Invitrogen; all other chemicals and reagents were obtained from Sigma Chemical.

\section{Statistical analysis}

Results are expressed as mean \pm SEM. The statistical analysis was performed using Statistica 6.3 software (Statsoft). The significance of differences between group means was determined using Student's $t$ test, one-way ANOVA, two-way ANOVA, or Mann-Whitney $U$ test, as indicated in each case. Differences between group means were considered significant if $p<0.05$. The results of statistical comparison of differences between group means are shown in the figure legend of each figure.

\section{Computational network model and simulations}

The model consists of a network of 200 excitatory (E) cells and 40 inhibitory (I) spiking neurons. Connections are such that each E cell receives inputs from $10 \%$ of the other $\mathrm{E}$ cells and $75 \%$ of the I cells. I cells receive connections from $75 \%$ of the E cells and I cells. Connections are either 0 or 1. Each neuron obeys the following dynamics (Izhikevich, 2004):

$$
\begin{gathered}
C \frac{d V}{d t}=I_{\text {appl }}+g_{l} \frac{\left(V-V_{l}\right)\left(V-V_{T}\right)}{V_{T}-V_{l}}-z\left(V-V_{K}\right)-I_{\text {syn }}+\sigma N \\
\frac{d z}{d t}=-a z,
\end{gathered}
$$

where $z$ represents adaptation, and $N$ is white noise. Each time $V(t)$ hits $V_{\text {spike }}, z$ is incremented by $d$ and $V$ is reset to $V_{r}$. For E cells, $g_{l}=0.05, V_{l}=$ $-65, V_{T}=-45, a=0.01, d=0.2, V_{r}=-52$. I cells are the same, but $g_{l}=0.1$ and $d=0$ (no spike-frequency adaptation). $V_{K}=-75$. $C$ is 1 $\mu \mathrm{F} / \mathrm{cm}^{2}$, all conductances are in millisiemens per square centimeter, and voltages are in millivolts. Parameters are chosen so that at rest $\mathrm{E}$ cells have a membrane time constant of $20 \mathrm{~ms}$ and I cells $10 \mathrm{~ms}$. Bias currents are 
applied only to the E cells, $I_{\text {appl }}=3 \mu \mathrm{A} / \mathrm{cm}^{2}$, so that the I cells can only fire if $\mathrm{E}$ cells fire. A small amount of white noise is added to the $\mathrm{E}$ cells.

Synaptic currents have the following form:

$$
I_{\text {syn }}=\left(g_{e} s_{e}+g_{n} s_{n}\right)\left(V-V_{\text {ex }}\right)+g_{i} s_{i}\left(V-V_{\text {in }}\right),
$$

where $V_{\text {in }}=-70$ and $V_{\text {ex }}=0$. Every neuron to which a given cell is connected contributes its own synaptic current. The synaptic gating variables satisfy the following equations:

$$
\begin{gathered}
\frac{d s_{e}}{d t}=-\frac{s_{e}}{\tau_{e}} \\
\frac{d s_{n}}{d t}=a_{n} s_{e}\left(1-s_{n}\right)-\frac{s_{n}}{\tau_{n}} \\
\frac{d s_{i}}{d t}=-\frac{s_{i}}{\tau_{i}} .
\end{gathered}
$$

Here $s_{n}$ is an NMDA synapse, $s_{e}$ is an AMPA synapse, and $s_{i}$ is GABA. The model for NMDA does not include any magnesium block, and its form is due to Wang (1999). Each time an E cell fires, $s_{e}$ is incremented by 1 ; each time an I cell fires, its corresponding $s_{i}$ is incremented by 1 . For $\mathrm{E} \rightarrow \mathrm{E}$ connections, $\tau_{e}=3 \mathrm{~ms}, g_{e e}=0.05$, and $g_{n e}=0.005$. For E $\rightarrow$ I connections, $g_{e i}=0.4, g_{n i}=0.002$, and $\tau_{e}=1 \mathrm{~ms}$. In both cases, $a_{n}=0.5 / \mathrm{ms}$ and $\tau_{n}=80 \mathrm{~ms}$. For I connections, $g_{i e}=0.5, g_{i i}=0.1$, and $\tau_{i}=2 \mathrm{~ms}$. All simulations were performed using XPPAUT; the code is available from the authors. Power spectra were taken on the "local field potential," which is the sum of all the excitatory currents into the excitatory cells. Rasters are actually plots of $s_{e}$ the $\mathrm{E} \rightarrow \mathrm{E}$ synaptic gating variables. Euler's method was used with a step size of $0.05 \mathrm{~ms}$.

\section{Results}

\section{Contribution of NMDAR-mediated currents to EPSCs}

We recorded from pyramidal cells and from FS interneurons in layer 5 of the medial PFC (Fig. 1A). FS interneurons are PVpositive cells with narrow spikes that lack spike-frequency adaptation, whereas non-FS interneurons are a largely heterogeneous group of PV-negative cells including multiple subclasses (Ascoli et al., 2008), most of which have significant spike-frequency adaptation and spikes with longer duration. Because several subclasses of non-FS interneurons have strong synaptic NMDAR currents (Lu et al., 2007; Wang and Gao, 2009), unambiguous identification of FS cells is crucial. We separated FS from non-FS interneurons based on the combined analysis (see Materials and Methods) of the spike duration at half peak amplitude, the spikefrequency adaptation (measured by the adaptation ratio), and the amplitude of the afterhyperpolarizing potential (AHP) observed following individual spikes (Fig. $1 B$ ). To confirm that the criteria were appropriate, we performed recordings from green fluorescent protein (GFP)-positive neurons from G42 mice (see supplemental Table 1, available at www.jneurosci.org as supplemental material), in which GFP is expressed exclusively in PV-positive FS neurons (Chattopadhyaya et al., 2004). As shown in Figure $1 B$, many non-FS cells have spikes significantly shorter than pyramidal cell spikes, together with obvious spike-frequency adaptation and/or relatively small AHP. Therefore, assessment of only the spike duration is insufficient for proper identification of FS neurons. In this study, we recorded from a total of 99 pyramidal neurons, 68 FS cells, and 45 interneurons that were classified as non-FS and therefore excluded from analysis of synaptic properties. All the recorded FS neurons for which morphology was identified were basket cells with multipolar aspiny dendrites (Fig. 1C). Examples illustrating the heterogeneous properties of the non-FS interneurons are shown in supplemental Figure 1 (available at www.jneurosci.org as supplemental material).
A Pyramidal

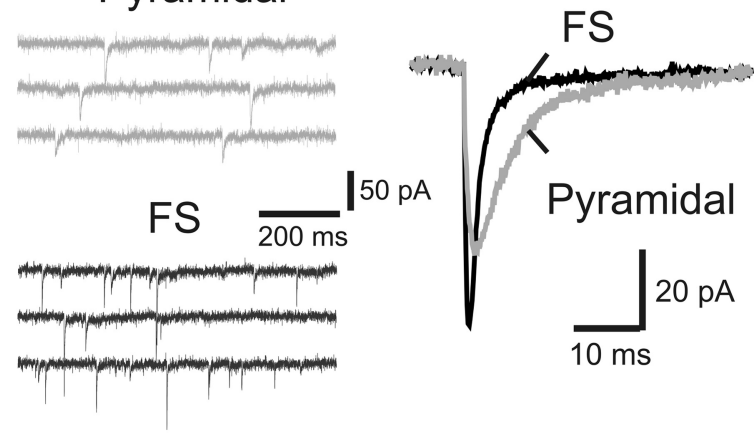

B Pyramidal

FS

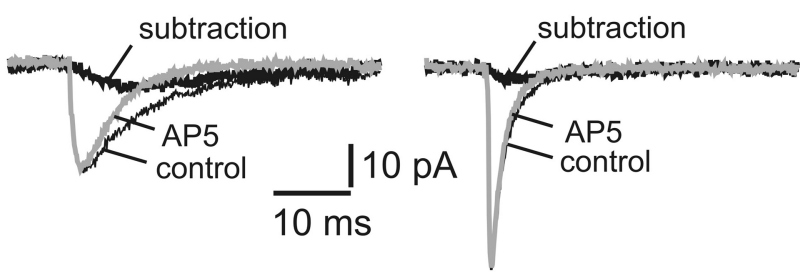

C

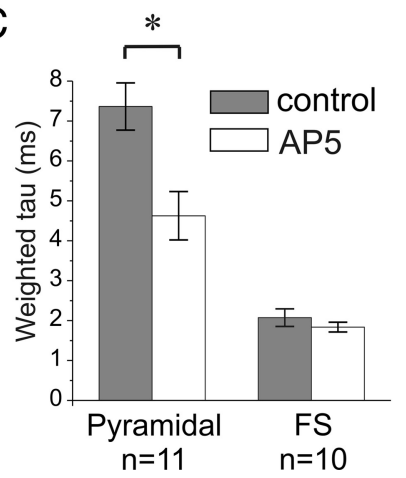

D

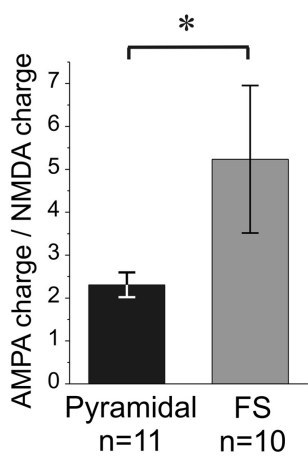

Figure 2. Contribution of AMPARs and NMDARs to sEPSCs in PFC neurons. $\boldsymbol{A}$, Left, Examples of sEPSC recorded from a pyramidal cell (gray) or a FS interneuron (black). Note the faster decay time course of individual sEPSCs in the FS neuron. Right, Averages of the sEPSCs recorded from the pyramidal cell and FS neuron are shown superimposed. $\mathrm{No} \mathrm{Mg}^{2+}$ was added to the extracellular solution. $\boldsymbol{B}$, Average sEPSCs recorded from a pyramidal cell (left) and a FS neuron (right) in control conditions (thin black), or after 15 min of D,L-AP5 (100 $\mu \mathrm{m}$ ) application (gray). The NMDAR-mediated sEPSC waveform obtained by subtraction is shown as well (thick black). $\boldsymbol{C}$, Bar graphs summarizing the differences in the decay time constant of the control average sEPSCs (AMPAR- and NMDAR-mediated) and the SEPSCs recorded after AP5 application (AMPAR-mediated). AP5 significantly accelerated the SEPSC decay in pyramidal cells but not in FS neurons. ${ }^{*} p<0.05$ (sEPSC decay time, pyramidal cells, $n=11$, control: $7.36 \pm 0.75 \mathrm{~ms}$, AP5: $4.63 \pm 0.22 \mathrm{~ms} ;$ FS cells, $n=10$, sEPSC: $2.04 \pm 0.20 \mathrm{~ms}$, AP5: $1.84 \pm 0.12 \mathrm{~ms}$; two-factor ANOVA, cell type: $F_{(1,38)}=89.9 p<0.00001$; NMDAR: $F_{(1,38)}=11.9 p<0.002$; interaction: $F_{(1,38)}=8.7 p<0.01$; post hoc Fisher LSD tests control versus AP5: pyramidal cells, $p<0.0001$, FS neurons: $p=0.736$ ). $D$, Bar graph showing the AMPA/NMDA charge ratio, estimated from the sEPSC waveforms for both pyramidal cells and FS neurons. * $p<0.01$ (AMPA/NMDA charge ratio, pyramidal cells, $n=11: 2.30 \pm 0.48 ;$ FS neurons, $n=10: 5.05 \pm 0.67$; Mann-Whitney $U$ test, $U=2.72, p<0.005$ ).

We recorded sEPSCs in $\mathrm{Mg}^{2+}$-free conditions (no $\mathrm{Mg}^{2+}$ added) to minimize NMDAR channel block, and found that the sEPSCs decayed more slowly in pyramidal cells than in FS interneurons (Fig. 2A). Because NMDAR-mediated EPSCs are significantly longer-lasting than AMPAR-mediated EPSCs (Dingledine et al., 1999; Cull-Candy and Leszkiewicz, 2004), we blocked NMDARs to test whether the slower sEPSC decay in pyramidal cells was associated with a stronger NMDAR contribution. Ketamine, a noncompetitive NMDAR antagonist com- 
monly used to model NMDAR hypofunction, was not used here because ketamine has multiple effects unrelated to its action as NMDAR antagonist. For instance, ketamine inhibits the hyperpolarization-activated channels (Chen et al., 2009), which are abundant in pyramidal cells (Kole et al., 2006) and FS neurons (Aponte et al., 2006) and shape the duration of synaptic responses (Magee, 1998; Rotaru et al., 2007). Ketamine also enhances the excitability of pyramidal cell dendrites (Potez and Larkum, 2008). Application of the competitive NMDAR antagonist AP5, significantly accelerated the sEPSC decay in pyramidal cells but not in FS neurons (Fig. 2B,C). The sEPSC peak amplitude was larger in FS neurons than pyramidal cells (Fig. $2 A, B$ ), but was not affected by AP5 in either cell type (sEPSC peak amplitude, pyramidal cells, $n=11$, control sEPSC: $30.4 \pm 2.1 \mathrm{pA}$; AP5 sEPSC: $29.9 \pm 2.5$ pA; FS neurons, $n=10$, control sEPSC: $42.0 \pm 5 \mathrm{pA}$; AP5 sEPSC: $36.4 \pm 4.7 \mathrm{pA}$; two-factor ANOVA, pyramidal vs FS: $F_{(1,38)}=5.91, p=0.019$; AP5: $F_{(1,38)}=0.686, p=0.412$; interaction: $\left.F_{(1,38)}=0.463, p=0.499\right)$. Waveform subtraction revealed a weaker NMDAR component in FS cell sEPSCs (Fig. $2 B$ ). Consequently, the AMPA/NMDA charge ratio (the ratio between the charge flowing through AMPARs and that flowing through NMDARs) was higher in FS neurons (Fig. 2D).

Our experiments using the competitive NMDAR antagonist AP5 may have underestimated the NMDAR contribution to FS cell sEPSCs if AP5 had weaker effects at FS neuron synapses. For instance, multivesicular glutamate release at FS cell synapses (Watanabe et al., 2005) may produce a high glutamate concentration transient in the synaptic cleft, thus displacing more strongly the competitive antagonist AP5 at FS versus pyramidal cell synapses. To estimate the NMDAR contribution independently of AP5 effects, we used CNQX, a high-affinity AMPAR antagonist whose efficacy is less affected by the cleft glutamate concentration (Biró and Nusser, 2005). Because detection of NMDAR-mediated sEPSCs after CNQX application was unreliable (supplemental Fig. 2, available at www.jneurosci.org as supplemental material), we studied EPSCs evoked with focal extracellular stimulation (eEPSCs) at low intensity, to minimize polysynaptic transmission, which in low $\mathrm{Mg}^{2+}$ is enhanced by NMDAR-mediated excitation (Thomson and West, 1986). AMPAR blockade revealed a significant NMDAR eEPSC in pyramidal neurons, whereas in FS cells the NMDAR eEPSC was smaller (Fig. $3 A, B)$. In either pyramidal cells or FS neurons, the EPSC component remaining after applying CNQX in $0 \mathrm{~mm} \mathrm{Mg}^{2+}$, was blocked by application of $\mathrm{Mg}^{2+}$ (1 mM), AP5 (Fig. 3A), or $\mathrm{Mg}^{2+}$ and AP5 together (supplemental Fig. 2, available at www. jneurosci.org as supplemental material). Moreover, the eEPSCs decayed more slowly in pyramidal cells than in FS neurons (Fig. $3 A, B)$, and waveform subtraction showed that NMDAR currents significantly prolonged the eEPSC decay in pyramidal cells and not in FS neurons (Fig. 3C). In addition, the AMPA/NMDA charge ratio for eEPSCs was significantly higher in FS cells (Fig. $3 D$ ). Therefore, as for sEPSCs, eEPSC properties suggest a weaker synaptic NMDAR contribution in FS cells.

Importantly, our data (Figs. 2, 3) show that the AMPARmediated EPSCs have a faster decay in FS neurons than in pyramidal cells ( $\mathrm{sEPSC}$ decay, FS cells, $n=10,1.84 \pm 0.12 \mathrm{~ms}$; pyramidal cells, $n=11,4.63 \pm 0.22 \mathrm{~ms}, p<0.001$; eEPSC decay, FS cells, $n=13,2.15 \pm 0.24 \mathrm{~ms}$; pyramidal cells, $n=10,4.78 \pm$ $0.38 \mathrm{~ms} ; p<0.001)$. These results suggest that compared with pyramidal cells, at glutamate synapses onto FS neurons fast signaling is optimized by having weaker NMDAR contribution and faster AMPAR currents. The mechanisms producing faster AMPAR currents in FS cells were not investigated here; however,
A Pyramidal
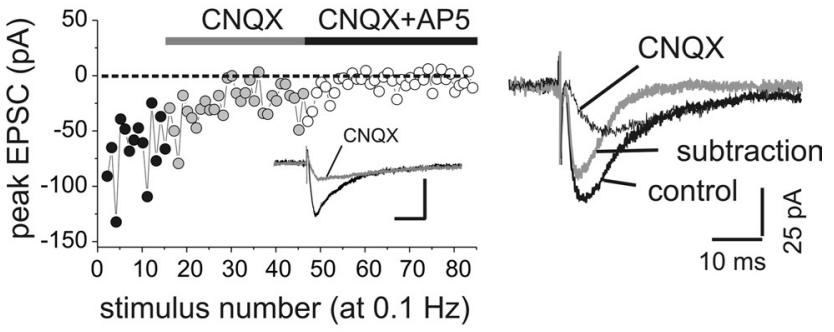

$\mathrm{B}$

FS
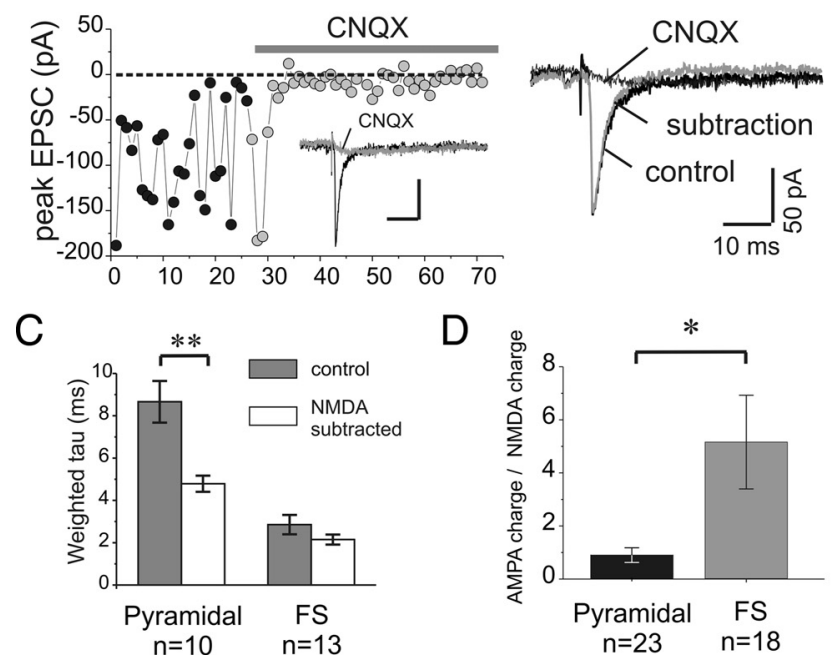

Figure 3. Contribution of AMPARs and NMDARs to eEPSCs in PFC neurons. A, Left, Plot of the response amplitude versus stimulus number for eEPSCs recorded from a pyramidal neuron, in control conditions and after application before of the AMPAR antagonist CNQX (20 $\mu \mathrm{M})$. Note that a significant eEPSC component was observed after CNQX application and was blocked by adding D, L-AP5 $(100 \mu \mathrm{M})$. No $\mathrm{Mg}^{2+}$ was added to the extracellular solution. The inset shows recordings from the neuron depicted in the plot (calibration bars: 50 pA, $20 \mathrm{~ms}$ ). Right, From recordings in a different pyramidal cell, shown superimposed are the average eEPSCs recorded in control conditions and after CNQX addition (thick and thin black, respectively) and the AMPAR-eEPSC waveform obtained by subtraction (gray). $\boldsymbol{B}$, Left, In an experiment similar to that shown in $\boldsymbol{A}$, a very small eEPSC was left in a FS neuron after CNQX application. Right, Average EPSCs and AMPA EPSC obtained by subtraction are shown superimposed for an example FS neuron. C, Bar graph summarizing differences in the decay time constant of the control eEPSCS (AMPAR- and NMDAR-mediated) and the AMPAR-mediated eEPSCs, obtained by waveform subtraction. ${ }^{* *} p<0.001$ (eEPSC decay time constant, pyramidal cells, $n=10$, control eEPSC: $8.86 \pm 0.98 \mathrm{~ms}$, AMPA eEPSC: $4.78 \pm 0.38 \mathrm{~ms} ;$ FS cells, $n=13$, control eEPSC: $2.85 \pm$ $0.46 \mathrm{~ms}$, AMPA eEPSC: $2.15 \pm 0.24 \mathrm{~ms}$; two-factor ANOVA, cell type: $F_{(1,42)}=59.4 p<$ 0.00001; NMDAR: $F_{(1,42)}=17.5 p<0.0002$; interaction: $F_{(1,42)}=8.4 p<0.01$; posthoc Fisher LSD tests control eEPSC vs AMPA eEPSC: pyramidal cells, $p<0.0001$, FS neurons, $p=0.704)$. $D$, Bar graph summarizing data of the AMPA/NMDA charge ratio, estimated from the eEPSC waveforms for both pyramidal cells and FS neurons. Relative to the AMPA charge, the NMDA charge was significantly smaller in FS neurons, producing a larger AMPA/NMDA charge ratio. ${ }^{*} p<0.05$ (AMPA/NMDA charge ratio, pyramidal cells, $n=23,0.87 \pm 0.28 ; \mathrm{FS}$ neurons, $n=18,5.21 \pm$ 1.79; Mann-Whitney $U$ test: $Z=2.022, p<0.05$ ).

in hippocampus and somatosensory cortex (Geiger et al., 1997; Angulo et al., 1999; Sambandan et al., 2010) as well as in rat PFC (Wang and Gao, 2010), AMPAR-EPSCs in FS cells seem to be mediated by GluR2 subunit-lacking AMPARs, which have fast deactivation and are $\mathrm{Ca}^{2+}$ permeable.

\section{Contribution of NMDARs to EPSPs}

The AMPA/NMDA charge ratios estimated for EPSCs showed a significantly weaker NMDAR component in FS cells. However, 

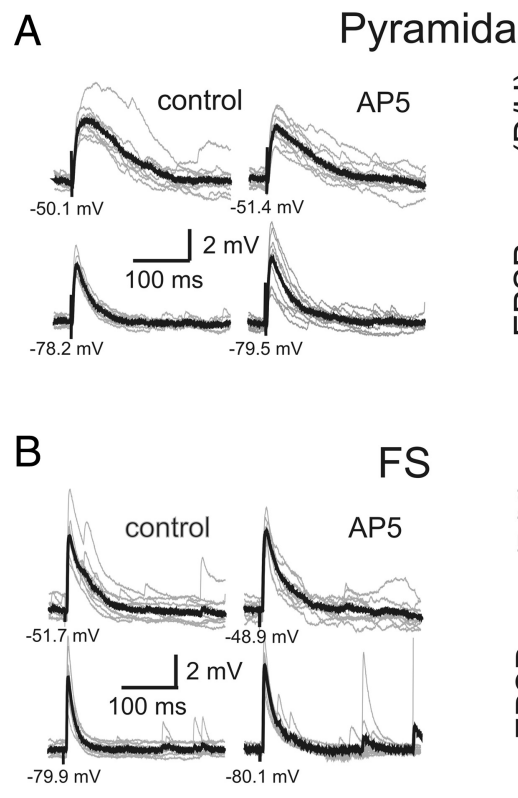

C

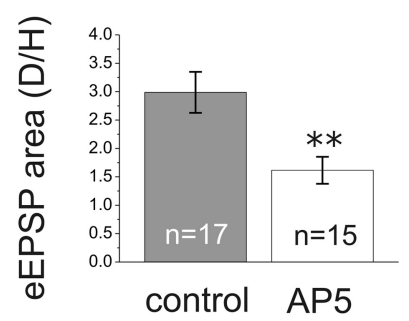

Pyramidal

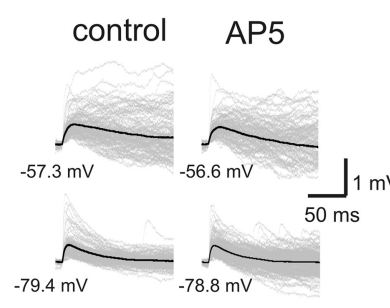

\section{Pyramidal}

D

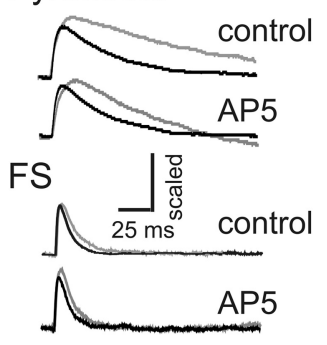

FS

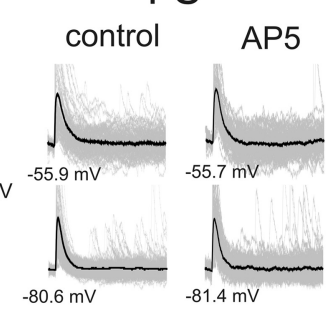

Figure 4. NMDAR contribution to EPSPs is significantly stronger in PFC pyramidal cells than in FS neurons. $A$, Left, eEPSPs in a pyramidal cell at negative potentials (approximately - $80 \mathrm{mV}$ ) and depolarized near spike threshold, in control conditions and after application of $\mathrm{D}, \mathrm{L}-\mathrm{AP5}(100 \mu \mathrm{M})$. Here and in $\boldsymbol{B}$ and $\boldsymbol{C}$, gray traces show individual eEPSPs and black traces the average of at least 10 eEPSPs. The numbers below the traces indicate the mean membrane potential measured $5 \mathrm{~ms}$ before stimulation. Right, The effects of depolarization and AP5 were estimated by computing the ratio between the eEPSP area at depolarized and hyperpolarized potentials (EPSP D/H area ratio). $\mathrm{D} / \mathrm{H}$ area ratio $=1$ means an absence of effect of depolarization (see Materials and Methods). The bar graph summarizes the experiments testing the effects of AP5 on EPSP D/H area ratio in pyramidal cells ${ }^{* *} p<0.01$ (eEPSP D/H area ratio for pyramidal cells, control: $2.98 \pm 0.36, n=17, \mathrm{AP5}$ : $1.61 \pm 0.24, n=15$; Mann-Whitney $U$ test $Z=2.63, p=0.0085) \cdot \boldsymbol{B}$, Left, eEPSPs evoked in a FS neuron at potentials near $-80 \mathrm{mV}$ and at a depolarized potential near spike threshold. Right, Bar graph summarizing the effects of membrane depolarization and D,L-AP5 (100 $\mu \mathrm{M}$ ) application on eEPSPs recorded from FS cells (eEPSP D/H area ratio for FS cells, control:2.10 $\pm 0.33, n=11, \mathrm{AP5}$ : $1.45 \pm 0.13, n=10$; Mann-Whitney $U$ test $Z=1.619, p=0.105$ ). FS interneurons were depolarized to similar subthreshold potentials than pyramidal cells (pyramidal cells, control: $-57.82 \pm$ $1.79 \mathrm{mV}$, AP5: $-56.15 \pm 1.66 \mathrm{mV}$; FS neurons, control: $-55.19 \pm 2.72 \mathrm{mV}$, AP5: $-54.11 \pm 4.11 \mathrm{mV}$; two-factor ANOVA followed by Fisher LSD comparisons, $p>0.25)$. C, Examples of sEPSPs recorded from a pyramidal cell (left panel) or a FS neuron (right panel) at different membrane potentials (average membrane potential values indicated below the traces). Gray traces show individual SEPSPs and black traces the average of at least 50 sEPSPs. D, Left, The average sEPSPs shown in Care displayed superimposed. Black traces and gray traces show the averages of $s$ EPSPs recorded at hyperpolarized and depolarized membrane potentials, respectively. Right, Bar graph summarizing the effects of membrane depolarization and D,L-AP5 (100 $\mu \mathrm{M})$ application on the sEPSP D/H area ratio. ${ }^{* *} p<0.005$ (sEPSP D/H area ratio for pyramidal cells, $n=8$, control: $3.28 \pm 0.33, \mathrm{AP5}: 1.87 \pm 0.22$, Mann-Whitney $U$ test $, Z=2.83, p=0.0045 ;$ FEPSP D/H area ratio for FS cells, $n=8$, control: $1.25 \pm 0.51, \mathrm{AP5}: n=8: 1.30 \pm 0.12$; Mann-Whitney $U$ test, $Z=0.210, p=0.833$ ). Pyramidal cells and FS neurons were depolarized to similar subthreshold membrane potentials before and during AP5 application (pyramidal cells, control: $-53.5 \pm 1.4 \mathrm{mV}$, AP5: $-55.0 \pm 1.5 \mathrm{mV}, p=0.655$; FS cells, control: $-55.9 \pm 2.5 \mathrm{mV}, \mathrm{AP5}:-54.4 \pm 3.2 \mathrm{mV}, p=0.641$ ).

the weaker NMDAR-mediated currents in FS cells may still be significant for EPSP-mediated FS cell excitation. Thus, we next compared the NMDAR contribution to EPSPs in pyramidal cells and FS neurons. In pyramidal cells, NMDAR-mediated currents prolong EPSPs specifically at depolarized potentials that decrease the voltage-dependent $\mathrm{Mg}^{2+}$ block of the NMDAR channel (Thomson, 1986, 1997; Forsythe et al., 1988; Jones and Baughman, 1988; Thomson et al., 1988). We therefore studied EPSPs evoked by extracellular stimulation (eEPSPs) in standard external $\mathrm{Mg}^{2+}(1$ $\mathrm{mM}$ ) at negative potentials (approximately $-80 \mathrm{mV}$ ) or during depolarization near spike threshold elicited by current injection into the soma of the recorded neuron.

At potentials near $-80 \mathrm{mV}$, the eEPSPs, which decayed with slower time course in pyramidal cells than FS neurons, were unaltered by AP5 application (Fig. $4 A, B$ ). In pyramidal cells, depolarization markedly prolonged the eEPSPs, which decayed in a highly nonexponential manner (Fig. 4B). In contrast, in depolarized FS neurons, eEPSPs were weakly prolonged and decayed nearly exponentially (Fig. 4B). NMDAR blockade attenuated the enhancement of eEPSPs by depolarization in pyramidal cells (Fig. $4 A$ ), whereas in FS neurons eEPSPs evoked at depolarized potentials were not significantly affected by AP5 (Fig. 4A). As the variable and highly nonexponential decay of EPSPs in depolarized pyramidal neurons prevented curve fitting, we estimated the effects of depolarization and AP5 measuring the ratio between EPSP area at depolarized relative to hyperpolarized potentials
(EPSP D/H area ratio, see Materials and Methods). In pyramidal cells, depolarization produced an $\sim 3$-fold increase in eEPSP area, and this effect was significantly attenuated, down to an $\sim 1.5$-fold increase, by AP5 (Fig. 4A). In FS neurons, depolarization produced a weaker, $\sim 2$-fold, increase in eEPSP area that was not significantly altered by AP5 (Fig. 4B).

AP5 nonsignificantly attenuated (from $\sim 2$-fold down to $\sim 1$.4-fold) the increase in eEPSP area with depolarization in FS neurons (Fig. 4B). Such nonsignificant decrease in the eEPSP area ratio by AP5 suggests that NMDARs contribute to the change in eEPSP area in FS neurons, but that such NMDAR contribution is significantly weaker than in pyramidal cells, as expected based on the sEPSC and eEPSC data (Figs. 2, 3). Importantly, extracellular stimulation may produce polysynaptic network activity, and since polysynaptic EPSPs overlap with the decay phase of monosynaptic EPSPs, they could lead to overestimation of the NMDAR contribution, confounding the measurements of EPSP area during depolarization even if the monosynaptic EPSPs are mostly AMPAR mediated. To confirm that NMDARs differentially contribute to monosynaptic EPSPs in pyramidal neurons versus FS cells, we tested the effects of AP5 on SEPSPs, which are produced in the absence of extracellular stimulation. Similar to the sEPSCs, at a hyperpolarized potential the sEPSPs had significantly larger amplitude in FS neurons than in pyramidal cells (FS sEPSP: $1.22 \pm 0.17 \mathrm{mV}, n=8$; pyramidal cell sEPSP: $0.61 \pm 0.09 \mathrm{mV}, n=8 ; p<0.01$ ), suggesting that 
single-synapse or unitary inputs are stronger in FS cells than in pyramidal neurons (Fig. 4C). Moreover, we found that depolarization increased the sEPSP area by $\sim 3$-fold in pyramidal cells and by $\sim 1.25$-fold in FS neurons (Fig. $4 D$ ), thus having effects that were very similar to those produced on eEPSPs (Fig. $4 B$ ). Application of AP5 significantly attenuated (down to an $~ 1.6-$ fold increase) the sEPSP area ratio in pyramidal cells (Fig. $4 D$ ), whereas in FS neurons the sEPSP area ratio was unaffected by AP5 (Fig. 4D). Together, the eEPSP and sEPSP recordings show that the NMDAR-mediated EPSP component is significantly stronger in pyramidal cells than in FS neurons. The decrease of eEPSP D/H area ratio by AP5 in FS neurons, even if not significant, raises some interesting questions given the absence of AP5 effect on sEPSP D/H area ratio. One possibility is that the nonsignificant decrease in eEPSP D/H area ratio by AP5 in FS neurons reflects blockade of the activation of an extrasynaptic pool of NMDARs that is not activated during sEPSPs, which mostly reflect single-synapse- and single-axon-mediated transmission. Extrasynaptic NMDARs may mediate the effects of glutamate spillover or ambient glutamate, both of which could influence FS neuron activation in specific network activity states, a possibility that remains to be investigated.

Importantly, the effect of depolarization on the eEPSP area was not completely prevented by NMDAR blockade (Fig. 4B), suggesting that together with NMDA-mediated currents, additional mechanisms underlie the increase in EPSP area with depolarization. For example, voltage-dependent conductances shape the EPSP area during depolarization of pyramidal cells and interneurons (Stuart and Sakmann, 1995; Magee, 1998; Fricker and Miles, 2000; Galarreta and Hestrin, 2001; González-Burgos and Barrionuevo, 2001; Rotaru et al., 2007). To test the role of voltage-dependent conductances, we generated EPSP-like voltage transients by injecting EPSC-like current waveforms (Rotaru et al., 2007) at hyperpolarized potentials or while depolarizing the cells near spike threshold with steady current injection (supplemental Fig. 3, available at www.jneurosci.org as supplemental material). Depolarization produced an AP5-insensitive increase in the area of the EPSP-like voltage transients, of $\sim 2.2$-fold in pyramidal cells and $\sim 1$.6-fold in FS neurons (supplemental Fig. 3 , available at www.jneurosci.org as supplemental material). These results show that depolarization shapes the EPSP area by the combined effects of NMDAR- and voltage-dependent conductances, as in somatosensory cortex pyramidal cells (Markram et al., 1997).

\section{Contribution of NMDARs to EPSP summation and EPSP-spike coupling}

The prolongation of EPSPs by NMDAR-mediated currents (Fig. 4) may enhance temporal summation in pyramidal cells. To test the NMDAR contribution to EPSP summation, we used focal stimulation to elicit trains of small EPSPs at hyperpolarized potentials or depolarized potentials near spike threshold. At potentials near rest, EPSPs decayed with slower kinetics in pyramidal cells than in FS neurons [decay time constant, pyramidal cell: $27.6 \pm 3.8 \mathrm{~ms}(n=7)$; FS neurons: $12.7 \pm 2.4 \mathrm{~ms}(n=6)$, Student's $t$ test, $t=3.158, p<0.01]$. Therefore, whereas in pyramidal cells EPSPs showed substantial summation at $20 \mathrm{~Hz}$, in FS neurons $50 \mathrm{~Hz}$ stimulation was necessary for summation of the fast-decaying EPSPs (supplemental Fig. 4, available at www. jneurosci.org as supplemental material). As shown in Figure 5, in pyramidal neurons membrane depolarization significantly enhanced EPSP summation, and this effect was attenuated by AP5 (Fig. 5A). In FS neurons, the increase in summation ratio at de-
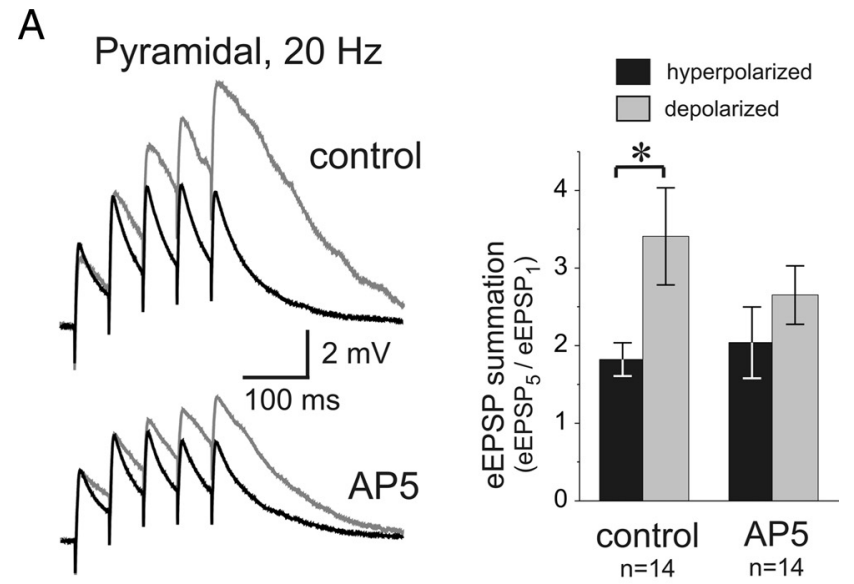

B
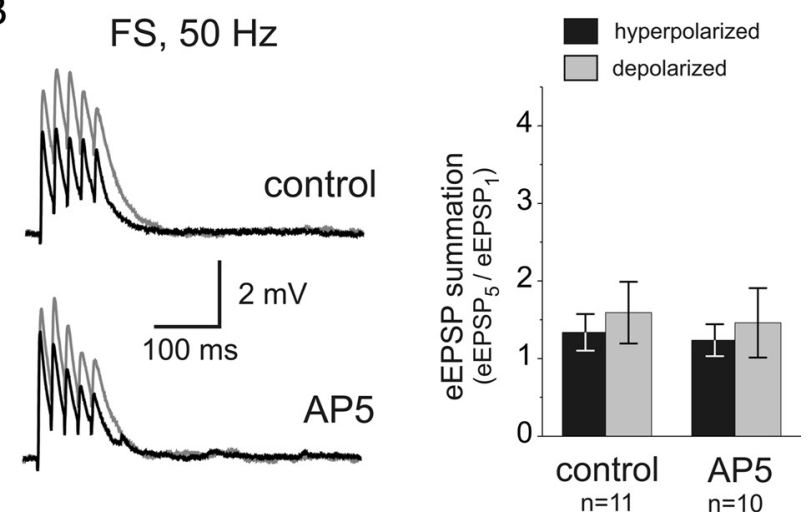

Figure 5. The NMDAR contribution to subthreshold EPSP summation is significantly stronger in PFC pyramidal cells than in FS neurons. $A$, Left, Example of average eEPSPs evoked by repetitive stimulation $(5$ stimuli, $20 \mathrm{~Hz}$ ) in a pyramidal cell recorded at approximately $-80 \mathrm{mV}$ (black trace) and at a depolarized membrane potential near threshold (gray trace). Right, Bar graph summarizing the differences in eEPSP summation at different membrane potentials in the absence or presence of the NMDAR antagonist D,L-AP5 $(100 \mu \mathrm{m}){ }^{*} p<0.02$ (eEPSP $/$ EEPSP $_{1}$ ratio, hyperpolarized: $1.82 \pm 0.21$, depolarized: $3.41 \pm 0.62, n=14, Z=2.113 p<0.05$, Mann-Whitney $U$ test; eEPSP /eEPSP $_{1}$ ratio hyperpolarized +AP5: $2.03 \pm 0.46$, depolarized +AP5: $2.65 \pm 0.37, n=12, Z=1.386 p=0.165$, Mann-Whitney $U$ test). The depolarized membrane potential in control and AP5 conditions did not differ significantly (control: $-59.5 \pm 2.7 \mathrm{mV}$; AP5: $-57.4 \pm 3.0 \mathrm{mV}, p=0.619) . \boldsymbol{B}$, Left, Example of average eEPSPs evoked by repetitive stimulation of excitatory inputs $(5$ stimuli, $50 \mathrm{~Hz}$ ) onto a FS cell recorded at approximately $-80 \mathrm{mV}$ (black traces) and at a depolarized membrane potential near threshold (gray traces). Right, Bar graph summarizing the differences in eEPSP summation at different membrane potentials in the absence or presence of the NMDAR antagonist D,L-AP5 $(100 \mu \mathrm{M})$ (eEPSP ${ }_{5} /$ EESP $_{1}$ ratio, hyperpolarized: $1.33 \pm 0.23 n=11$, depolarized: $1.59 \pm 0.39 n=10$, $Z: 0.281, p=0.778$, Mann-Whitney $U$ test; EEPSP $_{5} /$ EEPSP $_{1}$ ratio hyperpolarized $+\mathrm{AP5}: 1.24 \pm$ $0.20 n=9$, depolarized +AP5: $1.46 \pm 0.45, n=7, Z=0.0532, p=0.958$, Mann-Whitney $U$ test). The depolarized membrane potential in control and AP5 conditions did not differ significantly (control: $-55.9 \pm 1.9 \mathrm{mV}$; AP5: $-55.0 \pm 2.9 \mathrm{mV}, p=0.791$ ).

polarized potentials was significantly weaker than in pyramidal cells $(p<0.005)$ and was AP5 insensitive (Fig. 5B).

The NMDAR-mediated boosting of EPSP summation described in Figure 5 may potentiate EPSP-spike coupling more strongly in pyramidal cells. To test this possibility, we estimated the probability of eliciting spikes with trains of small EPSPs paired with postsynaptic depolarization produced by somatic current injection. In pyramidal neurons, spikes were evoked with significant delays and variable timing, following EPSP summation (Fig. 6A). In contrast, in depolarized FS neurons spikes typically were produced with short delays, within a narrow time window near the EPSP peak and independently of summation (Fig. $6 B$ ). The latency from the onset of the stimulus trains to the 
A

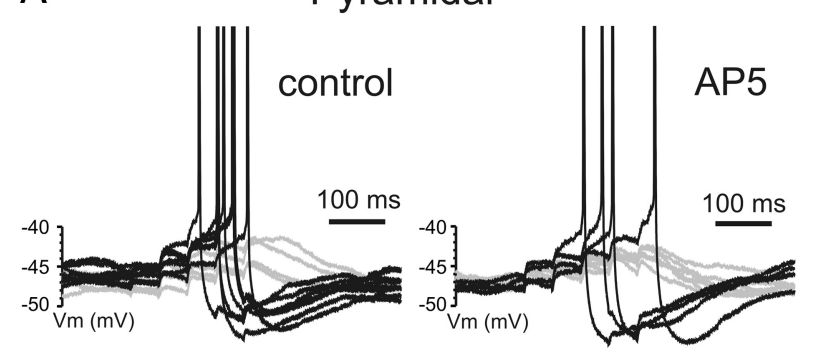

B

FS
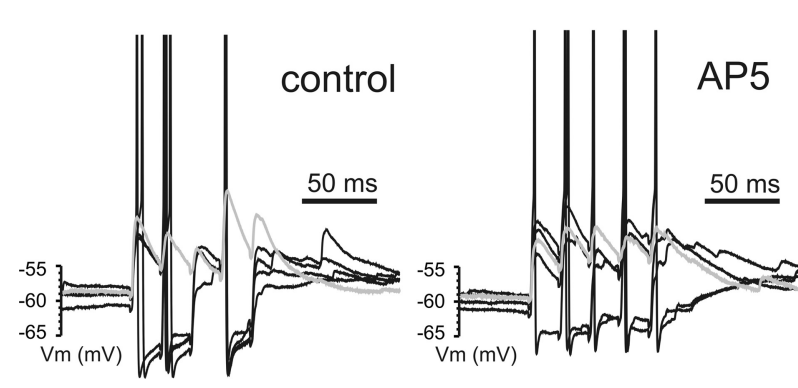

Figure 6. The NMDAR contribution to eEPSP-spike coupling is stronger in pyramidal cells. $\boldsymbol{A}$, Left, Consecutive traces showing eEPSP trains evoked by $20 \mathrm{~Hz}$ stimulation in a pyramidal cell at a depolarized membrane potential near spike threshold in control conditions. Middle, Recordings from the same neuron in the presence of D,L-AP5 (100 $\mu \mathrm{M})$. Here and in $\boldsymbol{B}$, subthreshold and suprathreshold eEPSP trains are labeled in gray and black, respectively. The spikes are truncated for easier visualization of the eEPSPs. Right, Bar graph illustrating the significant reduction of spike probability by D,L-AP5 (100 $\mu \mathrm{m})$ in pyramidal cells. ${ }^{*} p<0.05$ (probability of spiking, $n=6$, control: $0.67 \pm 0.12$, AP5: $0.36 \pm 0.16$, Student's $t$ test, $t=3.14, p<0.05$ ). $\boldsymbol{B}$, Left, Consecutive traces showing eEPSP trains evoked by $50 \mathrm{~Hz}$ stimulation in a FS neuron at a depolarized membrane potential near spike threshold in control conditions. Middle, Recordings in the presence of D,L-AP5 $(100 \mu \mathrm{M})$. The spikes are truncated for easier visualization of the eEPSPs. Right, Bar graph illustrating the absence of significant effect of D,L-AP5 (100 $\mu \mathrm{m})$ on spike probability in FS neurons (probability of spiking, $n=6$, control: $0.60 \pm 0.14$, AP5: $0.63 \pm 0.17$, Student's $t$ test, $t=0.233, p=0.824$ ).

first spike produced was significantly shorter in FS cells $(p<$ $0.00001)$, although the spike latency was not affected by AP5 in FS $(p=0.822)$ or pyramidal neurons $(p=0.664)$ (spike latency FS cells control: $39.9 \pm 9.9 \mathrm{~ms}$; FS cells AP5: $32.3 \pm 9.5 \mathrm{~ms}, n=6$; pyramidal cells control: $192.9 \pm 20.7 \mathrm{~ms}$; pyramidal cells AP5: $208.3 \pm 39.8 \mathrm{~ms}, n=6$ ). In addition the spike latency showed larger variability in pyramidal cells (SD of spike latency FS cells control: $24.4 \mathrm{~ms}$, FS cells AP5: $23.4 \mathrm{~ms}$; pyramidal cells control: $50.7 \mathrm{~ms}$, pyramidal cells AP5: $97.7 \mathrm{~ms}$ ). These data show that FS cells fire much earlier and with less variable timing relative to the onset of stimulation. NMDAR blockade with AP5 significantly decreased the firing probability in pyramidal cells (Fig. $6 \mathrm{~A}$ ), but did not affect the probability of FS cell firing (Fig. $6 B$ ). The stronger effect of AP5 on EPSP-spike coupling in pyramidal neurons was not attributable to a more depolarized baseline membrane potential in these cells, given that the mean membrane potential $10 \mathrm{~ms}$ before the onset of the EPSP trains did not differ significantly between cell types (pyramidal cells, $n=6$, control: $-55.8 \pm 3.2 \mathrm{mV}$; AP5: $-56.6 \pm 2.9 \mathrm{mV}$; FS neurons, $n=6$, control: $-55.0 \pm 4.1 \mathrm{mV}$; AP5: $-57.0 \pm 4.4 \mathrm{mV}$; two-factor ANOVA, cell type: $F_{(1,20)}=0.002, p=0.965$, NMDAR: $F_{(1,20)}=$ $0.145, p=0.707)$. Moreover, we found that the membrane potential value before the onset of the EPSP trains was not correlated with spike probability in neither pyramidal cells (Pearson's $r$ coefficient $=0.436, p=0.156$ ) or FS neurons (Pearson's $r$ coefficient $=0.0832, p=0.797)$, suggesting that the actual depolarization before train onset was not a determinant factor for spike probability.

The NMDAR contribution may increase if spikes are initiated by large EPSPs produced by synchronous activation of multiple

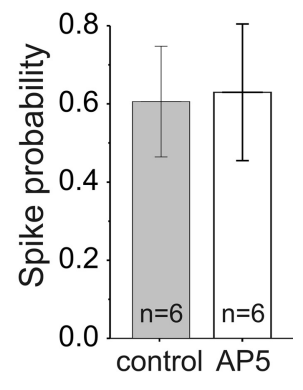

presynaptic axons. For instance, compared with depolarization by somatic current injection, large EPSPs may depolarize dendrites more efficiently, causing more significant relief of NMDAR channels from $\mathrm{Mg}^{2+}$ and producing, at least in pyramidal neurons, dendritic NMDA spikes (Schiller et al., 2000; Larkum et al., 2009). We tested whether synaptic activation by large EPSPs revealed a significant contribution of NMDARs in pyramidal cells or FS neurons. We found that NMDAR blockade depressed large EPSP-spike coupling more strongly in pyramidal neurons than in FS cells (supplemental Fig. 5, available at www.jneurosci.org as supplemental material), as observed in previous studies of somatosensory and motor cortex (Ling and Benardo, 1995; Karayannis et al., 2007).

\section{NMDAR antagonist effects on disynaptic IPSP-mediated inhibition of PFC pyramidal neurons}

EPSP-spike coupling in pyramidal cells may be counteracted by disynaptic inhibition evoked by glutamate-mediated excitation of interneurons synapsing onto the recorded cell. To test whether NMDARdependent disynaptic IPSPs inhibit EPSP-spike coupling in PFC pyramidal cells, next we evoked EPSPs followed by disynaptic IPSPs that partially truncated the EPSP decay phase (Fig. $7 A$ ). That the IPSPs were disynaptic was indicated by their variable trial-to-trial latency, significant failures, and their complete blockade by CNQX (Fig. 7B). During stimulus trains at depolarized potentials, spikes were observed in some trials, whereas in other trials spiking was apparently inhibited by the disynaptic IPSPs (Fig. $7 B)$. CNQX application completely blocked EPSPs and IPSPs (Fig. 7 $A, B$ ) showing minimal contribution from monosynaptic IPSPs. The $\mathrm{GABA}_{\mathrm{A}}$ receptor antagonist gabazine increased the spiking probability (Fig. 7C), showing that the disynaptic IPSPs inhibited pyramidal cell firing.

Disynaptic IPSPs are reduced by NMDAR antagonists in hippocampal pyramidal neurons (Ling and Benardo, 1995; Grunze et al., 1996), but are NMDAR-independent in somatosensory cortex (Ling and Benardo, 1995; Hull et al., 2009). Is NMDAR activation required to produce disynaptic IPSPs that control PFC pyramidal cell firing? If so, then NMDAR antagonists should increase the spike probability by removing or weakening the disynaptic IPSPs. To test this possibility, we applied MK801, a usedependent blocker of the NMDAR channels (Huettner and Bean, 1988), at a concentration $(10 \mu \mathrm{M})$ that saturates the NMDAR binding sites in equilibrium conditions. MK801 binding and channel block are dependent on NMDAR activation by glutamate (Huettner and Bean, 1988). Therefore, the effect of MK801 is predicted to be stronger at synapses in which the postsynaptic NMDAR contribution is greater or glutamate is released with a higher probability or reaches higher synaptic cleft concentrations. Figure $7 D$ shows that the main effect of MK801 was to decrease pyramidal cell firing, starting at an early time window following the onset of application, when the MK801 concentra- 
tion is probably still subsaturating. These data suggest that NMDARs are more critical to recruit pyramidal cells than interneurons producing the disynaptic IPSP-mediated inhibition in PFC slices.

Fast AMPAR-mediated excitation of FS neurons is important for synchronized oscillations in the gamma frequency band

FS neuron-mediated inhibition is crucial for the production of synchronized gamma band oscillations (Whittington et al., 2000; Bartos et al., 2007; Mann and Paulsen, 2007; Hájos and Paulsen, 2009). Current models suggest that during gamma oscillations FS neurons are recruited by rhythmic EPSCs synchronized with the network oscillation (Mann et al., 2005a; Oren et al., 2006; Cardin et al., 2009; Sohal et al., 2009). Such rhythmic EPSCs recruit FS cells in most cycles of the gamma oscillation, providing the feedback inhibition that synchronizes the pyramidal cells (Whittington et al., 2000; Mann et al., 2005b; Hájos and Paulsen, 2009). Our experiments show that glutamate synapses onto FS neurons have weaker NMDAR contribution and faster AMPAR currents than those onto pyramidal cells. One possibility is that the fast EPSC kinetics in FS neurons is important for interneuron activation during pyramidal cell-FS neuron feedback loops involved in gamma oscillations. To address this issue, we performed simulations in a model network of pyramidal and FS cells (Fig. $8 A$ ), reciprocally connected via excitatory and inhibitory synapses with properties consistent with those mediated by AMPARs, NMDARs, and $\mathrm{GABA}_{\mathrm{A}}$ receptors (Fig. $8 \mathrm{~B}$ ). Pyramidal cells continuously received noisy and heterogeneous excitatory drive, which in the absence of feedback inhibition produced network activity with no significant power in the gamma band (data not shown). No excitatory drive was directly applied onto FS cells, which therefore fired exclusively in response to EPSCs produced by pyramidal cell inputs. In the presence of $\mathrm{GABA}_{\mathrm{A}}$ receptor-mediated feedback inhibition from the FS cells, we manipulated the strength of the AMPAR- and NMDAR-mediated conductance at the excitatory connections from pyramidal cells onto FS neurons $\left(g_{e i}\right.$ and $g_{n i}$, respectively), with other network parameters remaining constant. With AMPAR-dominated synapses $\left(g_{e i}=0.4 \mathrm{mS} / \mathrm{cm}^{2} ; g_{n i}\right.$ $=0.002 \mathrm{mS} / \mathrm{cm}^{2}$ ), network activity was highly synchronized (Fig. $8 C$ ), showing a dominant component in the gamma frequency band (Fig. $8 E$ ). Increasing the NMDAR contribution (increasing $g_{n i}$ from 0.002 to $0.008 \mathrm{mS} / \mathrm{cm}^{2}$ ) decreased rhythmicity (Fig. $8 D$ ), the oscillation power decreasing in an NMDAR-dependent manner (Fig. $8 E$ ). Importantly, the simulations were performed in the absence of $\mathrm{Mg}^{2+}$ block, since otherwise very large $g_{n i}$ values were necessary to produce significant effects (data not shown), possi-
B
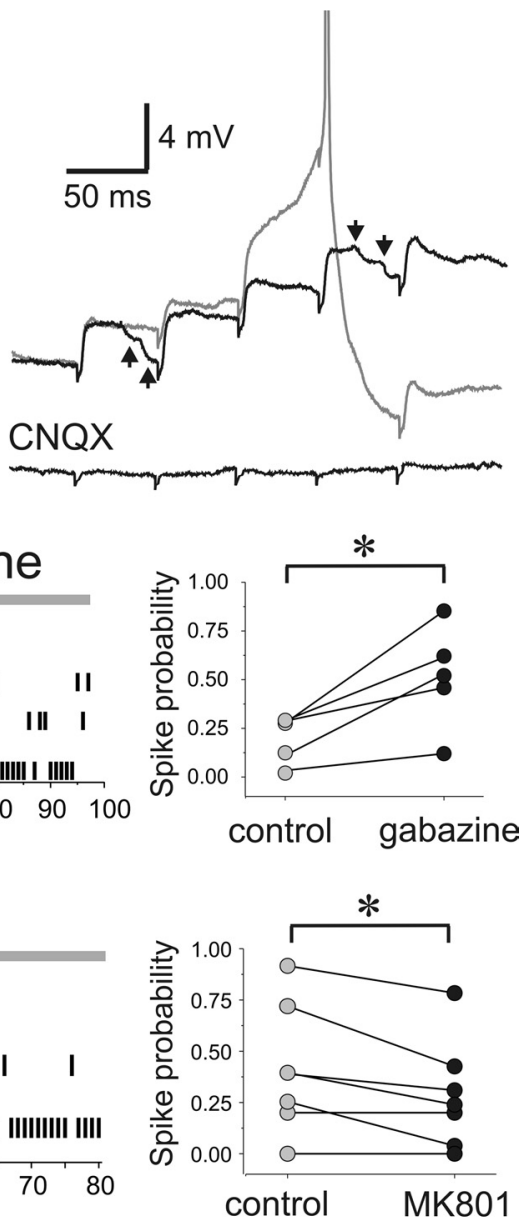

Figure 7. NMDAR contribution to disynaptic inhibition onto PFC pyramidal cells. $\boldsymbol{A}$, Top, Three traces showing that longdistance lateral stimulation of synaptic inputs produced, in a pyramidal cell, a sequence of an EPSP followed by disynaptic IPSPS arrows), which strongly truncated the decay phase of the EPSP. Note that the disynaptic IPSPs had variable latency from trial to (t) train frequency: $20 \mathrm{~Hz}$ ). Note that application of the $\mathrm{GABA}_{\mathrm{A}}$ receptor antagonist gabazine (2 $\mu \mathrm{m}$ ) increased firing. Right, Graph summarizing the effect of gabazine application on the spiking probability. ${ }^{*} p<0.05$ (spike probability: control, $0.19 \pm 0.05$, gabazine, $0.51 \pm 0.12, p<0.05, t=3.618, n=5$, Student's $t$ test). $\boldsymbol{D}$, Left, Graph showing the number of spikes per EPSP train summarizing the effect of MK801 application on the spiking probability. ${ }^{*} p<0.05$ (spike probability: control, $0.41 \pm 0.12$, MK801, $0.28 \pm 0.10, p<0.05, t=3.048, n=7$, Student's $t$ test).

bly because the fast time course of FS neuron EPSCs precludes significant relief from $\mathrm{Mg}^{2+}$ block.

How does the increase of NMDAR conductance at pyramidalto-FS synapses decrease the power of the gamma rhythm? To understand how increasing $g_{n i}$ disrupts the gamma oscillation, we examined the inputs onto a typical FS cell during the rhythm. Figure $8, F$ and $G$, the show the total current entering the FS cell (black trace), along with the synaptic output of that FS cell (red trace), and the activity of the pyramidal cells (the scaled total AMPA output of the pyramidal cell population, green trace). Note that a smaller NMDAR synaptic current at inputs onto FS neurons $\left(g_{n i}=0.002 \mathrm{mS} / \mathrm{cm}^{2}\right.$ ) (Fig. $8 F$ ) leads to a flat and low amount of input between bouts of firing and that the output of the FS cell is closely time-locked to the peaks in the total input (black peaks), which are, in turn, tightly locked to the excitatory activity (green trace). However, with higher amounts of synaptic 
A

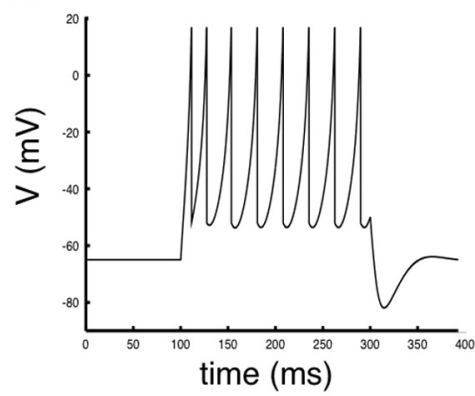

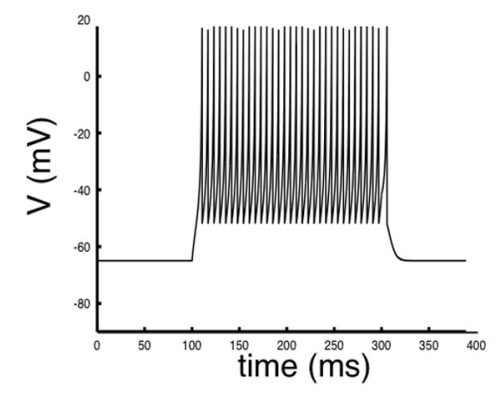

D E cells I cells

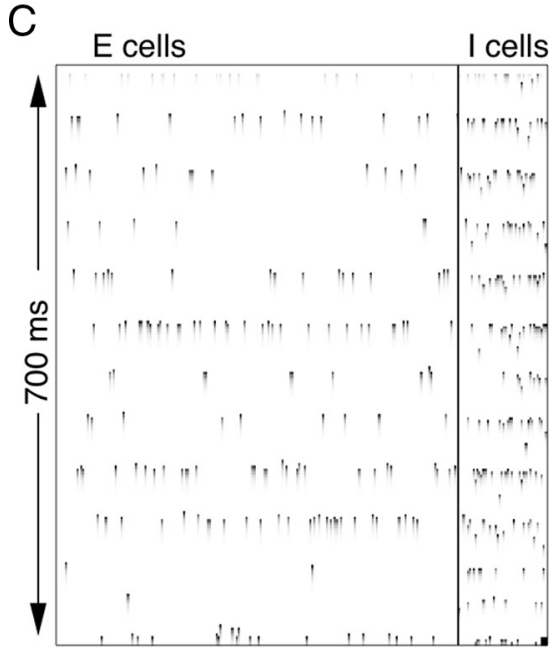

$\mathrm{F}$

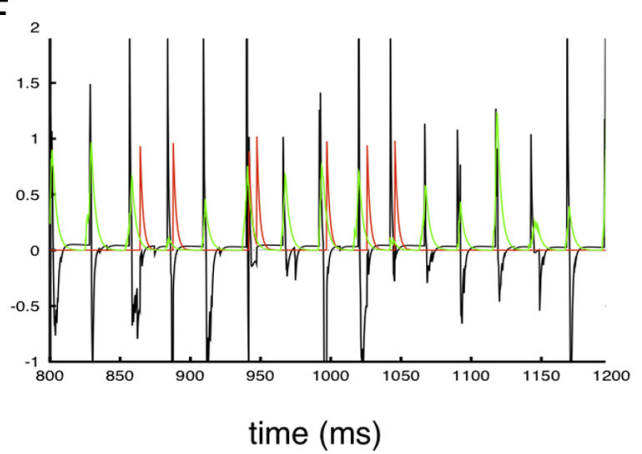

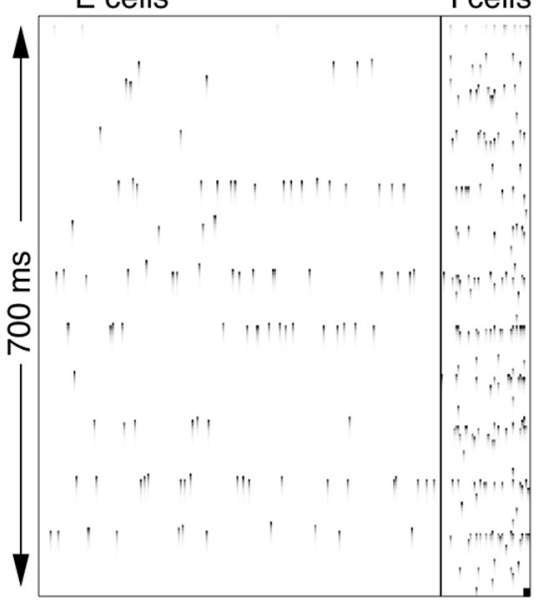

G
B

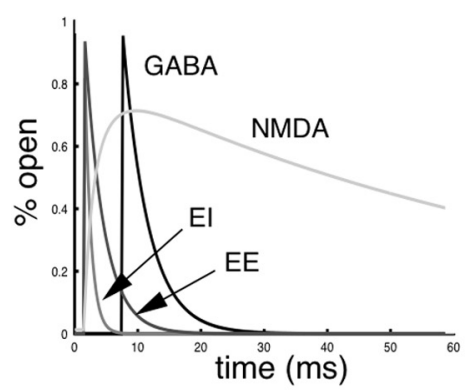

E

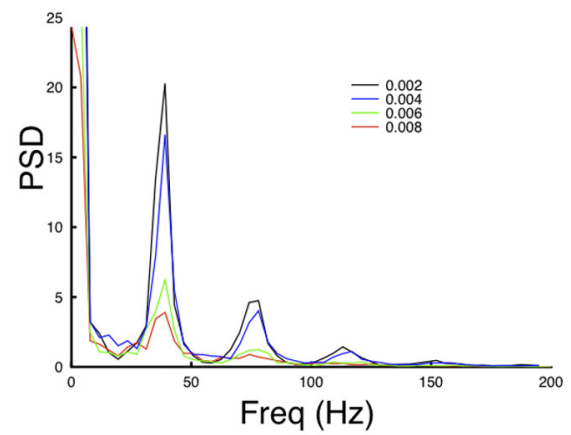

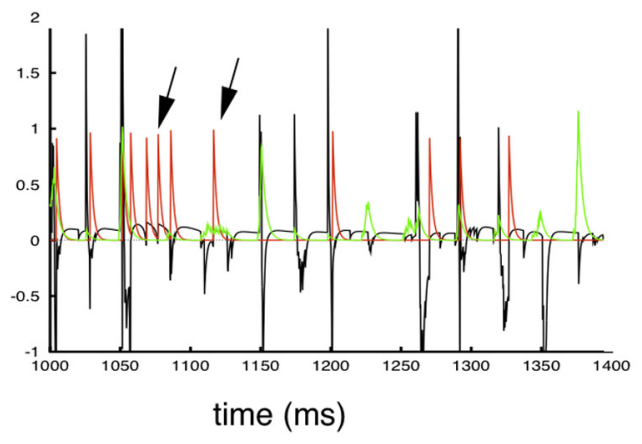

Figure 8. Fast AMPAR-mediated FS neuron activation is crucial for production of gamma oscillations via feedback mechanisms. $\boldsymbol{A}$, Membrane properties of E cells (which represent pyramidal neurons) and I cells (which represent FS neurons) in the model network. $B$, Time course of synaptic conductances used to model excitatory and inhibitory synapses between model neurons. Note that the decay of the AMPA conductance is faster at excitatory synapses onto I cells (El) than at excitatory synapses onto E cells (EE). In addition, the decay time of NMDA conductance is significantly longer than the decay of El or EE. C, Raster plot showing the spike timing of E cells (left columns) and I cells (right columns) during a network oscillation episode produced in conditions of relatively low NMDAR conductance in the excitatory synapses onto I cells $\left(g_{n i}=0.002 \mathrm{mS} / \mathrm{cm}^{2}\right.$, see Materials and Methods). D, A raster plot similar to that shown in $\boldsymbol{C}$, but obtained during an episode of network activity in conditions of higher NMDAR conductance in excitatory synapses onto I cells ( $g_{n i}=0.008 \mathrm{mS} / \mathrm{cm}^{2}$ ). , Plot of power spectral density (PSD) showing the effects of different strengths of $g_{n i}$ on network activity. Note that larger values of $g_{n i}$ produced a decrease in oscillation in power and synchrony. $\boldsymbol{F}$, Plot of the time course of the total current entering a typical I cell (black trace), the synaptic output of that FS cell (red trace), and the activity of the pyramidal cells (the scaled total AMPA output of the pyramidal cell population, green trace). These variables, shown in arbitrary units in the $y$-axis (negative values for the black grace indicate hyperpolarizing/outward current), were computed for network activity produced with a $g_{n i}=0.002 \mathrm{mS} / \mathrm{cm}^{2}$. Note the rhythmic input onto the I cell and the regular output from this I cell onto other cells in the network. $G$, A plot equivalent to that shown in F, for network activity produced with $g_{n i}=0.008 \mathrm{mS} / \mathrm{cm}^{2}$. Note that in this case, the input currents onto the FS cell remain elevated between spikes (note the much higher levels of the black curves between peaks) and can result in spikes or bursts of spikes from the FS cell that are not locked to the excitatory activity (arrows).

NMDA current onto the FS cells $\left(g_{n i}=0.008 \mathrm{mS} / \mathrm{cm}^{2}\right)$ (Fig. $8 G$ ), the input currents to the FS cell remain elevated between spikes (note the much higher levels of total input current between peaks) and can result in spikes or bursts of spikes from the FS cell that are not locked to the excitatory activity (Fig. 8G, arrows). This extra firing of the FS cells that is not tightly locked to activity disrupts the rhythm and results in the decrease in power and synchrony. The results from our simulations are consistent with experiments in vitro showing that NMDAR blockade does not affect gamma oscillations that are, however, abolished by AMPAR antagonists (Traub et al., 1996; Buhl et al., 1998; Fisahn et al., 1998; LeBeau et al., 2002; Cunningham et al., 2006; Roopun et al., 2008). Moreover, in some in vivo and in vitro studies NMDAR blockade increased the gamma oscillation power (Pinault, 2008; Roopun et al., 2008; Hakami et al., 2009; Pietersen et al., 2009; Hong et al., 2010), consistent with the effect of lowering $g_{n i}$ in our simulations.

Finally, we addressed the effect of changing the strength of NMDAR conductance onto FS neurons, in a model network in- 
cluding FS cells and a population of non-FS inhibitory neurons that may also be involved in the mechanisms of gamma oscillations. Such non-FS cells form a population of interneurontargeting cells that are PV-negative, have spike-frequency adaptation, and synapse among themselves and onto FS neurons but not onto pyramidal cells (Mann et al., 2005a). During gamma oscillations, such interneuron-targeting cells are highly active and fire in a manner tightly coupled to the gamma oscillation cycle (Mann et al., 2005a), although their role in the gamma oscillation mechanisms is poorly understood. In our model, these cells were called FS cell-targeting inhibitory units (FTUs). We run simulations (supplemental Fig. 6, available at www.jneurosci.org as supplemental material) in a modified model network including FTUs that receive the same type and strength of excitatory inputs from pyramidal cells, and target other FTUs and FS neurons, but not the pyramidal cells. Simulations were done in two different cases, changing the strength of NMDA at inputs onto FSU/FTU cells from a "normal" low value to a high value. The results shown in supplemental Figure 6 (available at www. jneurosci.org as supplemental material) indicate that the presence of the FTUs does not change the effect of increasing the NMDA strength to FS neurons, which is disruptive to the gamma power. We can conclude that adding a non-FS population of inhibitory cells has no qualitative effect on the outcome of the modeling regarding the role of NMDA currents.

\section{Discussion}

\section{Fast synaptic excitation with weak NMDAR contribution in PFC FS neurons}

We compared the mechanisms of synaptic activation of FS neurons and pyramidal cells in mouse PFC, focusing on the relative contribution of NMDARs and AMPARs, as this relation is important to determine the possible cellular substrates and network consequences of NMDAR hypofunction in PFC circuits. We found that FS cells had EPSCs with faster decay due to a weaker contribution of NMDAR currents, which typically produce longlasting EPSCs. These synaptic properties in PFC FS neurons are consistent with findings of short-lasting EPSCs and weak NMDAR component in FS/PV-positive interneurons from other cortical and subcortical areas (Geiger et al., 1995, 1997; Angulo et al., 1999; Goldberg et al., 2003; Nyíri et al., 2003; Lamsa et al., 2007; Lu et al., 2007; Hull et al., 2009; Gittis et al., 2010).

Importantly, the NMDARs present in FS neurons predominantly contain NR2A subunits (Kinney et al., 2006), which, among NR2 subunits, produce the fastest NMDA EPSC decay (Dingledine et al., 1999; Cull-Candy and Leszkiewicz, 2004). NR2A subunits determine strong $\mathrm{Mg}^{2+}$ block, possibly explaining the higher sensitivity to $\mathrm{Mg}^{2+}$ of NMDAR-mediated EPSCs in FS neurons (Hull et al., 2009). Furthermore, we found that the decay of AMPAR-mediated EPSCs is faster in FS neurons than in pyramidal cells, a finding possibly attributed to the predominance of GluR2-lacking, rapidly deactivating AMPARs (Geiger et al., 1997; Angulo et al., 1999; Hull et al., 2009; Nissen et al., 2010; Wang and Gao, 2010). Therefore, synaptic properties and specific biophysical features of their dendrites (Hu et al., 2010), contribute to a fast and temporally precise synaptic activation of FS neurons.

One possibility is that the NMDAR currents underlying EPSCs in FS neurons, although small, are nevertheless crucial for EPSP-spike coupling. If so, then a reduction of synaptic NMDAR currents in schizophrenia or by NMDAR antagonists would depress FS cell activity more than pyramidal cell firing. However we found that, in contrast to pyramidal cells, NMDARs have a small impact on EPSP-spike coupling in FS neurons. Moreover, in FS neurons EPSP summation required a shorter time window, was more weakly enhanced by depolarization and was less affected by NMDAR blockade. Therefore, our results suggest that EPSPspike coupling in FS cells occurs via NMDAR-independent coincident detection, whereas in PFC pyramidal neurons EPSP summation and EPSP-spike coupling were consistent with NMDAR-dependent temporal integration.

\section{Are NMDARs important to recruit FS neuron-mediated inhibition in PFC circuits?}

It has been proposed that NMDAR hypofunction produces disinhibition based on the assumption that FS neuron excitation is highly sensitive to NMDAR antagonists (Lisman et al., 2008). However, here we show that FS cell excitation is less sensitive to NMDAR antagonists than is pyramidal cell excitation, because FS cells have EPSCs with a weak NMDAR component, possibly contributing to the rapid coupling of excitation with inhibitory output (Jonas et al., 2004; Hu et al., 2010). In fact, robust long-lasting NMDA EPSCs at pyramidal-pyramidal synapses in PFC (Wang et al., 2008) may be critical for recurrent excitation and working memory (Lisman et al., 1998; Wang, 1999). Therefore, acting locally, NMDAR antagonists appear unlikely to produce FS neuron-mediated disinhibition.

To test whether NMDAR antagonists produce disinhibition in PFC circuits, we performed experiments in conditions in which disynaptic IPSPs inhibited EPSP-spike coupling in pyramidal cells. In these conditions, pyramidal cell firing was enhanced by a GABA receptor antagonist, consistent with disinhibition, but was decreased by NMDAR blockade. Consistent with these findings, disynaptic IPSP recruitment is NMDAR-independent in somatosensory cortex (Ling and Benardo, 1995; Hull et al., 2009), although it is NMDAR-dependent in hippocampal circuits (Ling and Benardo, 1995; Grunze et al., 1996).

Here, and in previous studies (Ling and Benardo, 1995; Grunze et al., 1996), the interneuron subtypes mediating disynaptic inhibition were not identified. Other studies showed that FS neurons produce NMDAR-independent disynaptic IPSPs (Hull et al., 2009; Pouille et al., 2009). NMDAR-dependent disynaptic inhibition may be produced by non-FS/PV-negative neurons, which have synapses with strong NMDAR contribution (Lamsa et al., 2007; Lu et al., 2007; Wang and Gao, 2009). Non-FS neurons, including those in PFC, indeed elicit disynaptic IPSPs, but it has not been determined whether these are NMDAR-dependent (Kapfer et al., 2007; Silberberg and Markram, 2007; Berger et al., 2009).

To compare the effects of fast AMPAR-mediated versus slow NMDAR-mediated excitation of FS neurons on the mechanisms of gamma oscillations, we studied a model network producing gamma rhythms via feedback inhibition. We found that AMPAR-mediated FS neuron excitation was sufficient to support gamma oscillations, consistent with experiments showing that AMPAR blockade and AMPAR deficiency in PV neurons, but not NMDAR blockade, strongly attenuate gamma oscillations (Traub et al., 1996; Buhl et al., 1998; Fisahn et al., 1998; LeBeau et al., 2002; Cunningham et al., 2006; Fuchs et al., 2007; Roopun et al., 2008). Conversely, decreases in the slow NMDA conductance at pyramidal-FS neuron synapses increased gamma power in the network model. Similarly, NMDAR antagonists enhance gamma power in animal models (Pinault, 2008; Roopun et al., 2008; Hakami et al., 2009; Pietersen et al., 2009) or human subjects (Hong et al., 2010). Our simulations therefore suggest that rapid FS neuron activation (Jonas et al., 2004; Hu et al., 2010) is crucial for the production of gamma oscillations. 


\section{Implications for models of schizophrenia pathophysiology} Our findings studying the synaptic activation of PFC FS interneurons raise interesting questions about the mechanisms that might link NMDAR hypofunction to reduction of PV and GAD67 expression. Because lower levels of PV facilitate GABA release (Vreugdenhil et al., 2003), we suggested that decreased PV in schizophrenia is a compensatory response to a GAD67 deficit that reduces GABA synthesis and release (Lewis et al., 2005; Gonzalez-Burgos and Lewis, 2008). Therefore, PV reduction by NMDAR hypofunction may be secondary to a primary decrease of GAD67 levels. If so, a crucial question is how NMDAR hypofunction leads to reduced GAD67 expression in FS cells. One possibility is that changes in network activity are involved, because activity is the main factor regulating GAD67 expression (Jones, 1990; Akbarian and Huang, 2006). For example, deprivation of afferent activity decreases GAD67 levels and inhibitory synaptic strength (Benson et al., 1994; He et al., 2006; Jiao et al., 2006). Conversely, cortical network hyperactivity increases GAD67 (Liang and Jones, 1997; Esclapez and Houser, 1999). Interestingly, NMDAR blockade depresses the so-called up states in vitro (Tu et al., 2007; Kroener et al., 2009) and in vivo (Steriade et al., 1993; Seamans et al., 2003), thus producing network hypoactivity. Cortical up states recruit pyramidal cells (Lewis and O'Donnell, 2000; Waters and Helmchen, 2006) and FS interneurons (Puig et al., 2008; Gentet et al., 2010) and involve local recurrent excitation and feedback inhibition (Fellous and Sejnowski, 2003; McCormick et al., 2003; Hasenstaub et al., 2005). Therefore, NMDAR antagonists may decrease GAD67 via network hypoactivity produced by up-state depression.

Somewhat contrasting with up-state depression, systemically administered NMDAR antagonists can increase PFC pyramidal cell activity in vivo (Suzuki et al., 2002; Homayoun and Moghaddam, 2007; Kargieman et al., 2007). Increased activity could reflect disinhibition, since NMDAR antagonists depress the in vivo activity of putative interneurons (Homayoun and Moghaddam, 2007), although a substantial fraction ( 33\%) of PFC cells depressed by NMDAR antagonists are pyramidal (Kargieman et al., 2007). Our finding that FS cells are less sensitive to NMDAR antagonism than pyramidal neurons suggests that the disinhibition produced by NMDAR antagonists acting locally is mediated by non-FS interneurons that have strong NMDAR-mediated EPSCs (Lu et al., 2007; Wang and Gao, 2009).

Alternatively, systemically applied NMDAR antagonists could increase PFC neuron activity indirectly, via simultaneous action in multiple brain regions. For instance, PFC pyramidal cell firing in vivo is increased by intrahippocampal infusion of NMDAR antagonists, but is decreased or is not altered by intra-PFC infusion (Suzuki et al., 2002; Jodo et al., 2005). Moreover, NMDAR antagonists may significantly depress the firing of ventral tegmental area neurons (Tseng et al., 2006; Zweifel et al., 2009), whose projections onto PFC inhibit pyramidal cells (Pirot et al., 1992; Lewis and O'Donnell, 2000) and excite FS neurons (Tseng et al., 2006).

In a strain of genetically modified mice generated recently, NMDARs can be deleted selectively in GABA neurons, including PV cells (Belforte et al., 2010). NMDAR deletion in these mice failed to produce significant effects unless the deletion was induced during very early development, in which case adult mice developed schizophrenia-like behavioral alterations (Belforte et al., 2010). Interestingly, excitatory inputs onto immature PV neurons have strong NMDAR currents that progressively weaken with age, becoming small or absent in adult PV neurons (Wang and Gao, 2009, 2010). Similarly, in the cortex of adult human subjects, $\sim 70 \%$ of the PV-positive neurons have undetectable levels of NMDAR subunit mRNA (Bitanihirwe et al., 2009). Because NMDARs are essential for the maturation of excitatory synapses (Waites et al., 2005), NMDAR subunit deletion early in development may persistently affect behavior into adulthood (Belforte et al., 2010) by disrupting the maturation of FS cell connectivity. However, the NMDAR hypofunction hypothesis of schizophrenia is primarily based on the effects of NMDAR antagonists administered to adult animals or adult human subjects (Javitt and Zukin, 1991). Our results and previous data (Wang and Gao, 2009; Belforte et al., 2010) suggest that NMDAR hypofunction induced in the adult state may affect PFC function by acting at glutamate synapses different from those mediating the activation of FS/PV-positive cells.

\section{References}

Akbarian S, Huang HS (2006) Molecular and cellular mechanisms of altered GAD1/GAD67 expression in schizophrenia and related disorders. Brain Res Rev 52:293-304.

Angulo MC, Rossier J, Audinat E (1999) Postsynaptic glutamate receptors and integrative properties of fast-spiking interneurons in the rat neocortex. J Neurophysiol 82:1295-1302.

Aponte Y, Lien CC, Reisinger E, Jonas P (2006) Hyperpolarizationactivated cation channels in fast-spiking interneurons of rat hippocampus. J Physiol 574:229-243.

Ascoli GA, Alonso-Nanclares L, Anderson SA, Barrionuevo G, BenavidesPiccione R, Burkhalter A, Buzsáki G, Cauli B, Defelipe J, Fairén A, Feldmeyer D, Fishell G, Fregnac Y, Freund TF, Gardner D, Gardner EP, Goldberg JH, Helmstaedter M, Hestrin S, Karube F, et al. (2008) Petilla terminology: nomenclature of features of GABAergic interneurons of the cerebral cortex. Nat Rev Neurosci 9:557-568.

Bartos M, Vida I, Jonas P (2007) Synaptic mechanisms of synchronized gamma oscillations in inhibitory interneuron networks. Nat Rev Neurosci 8:45-56.

Behrens MM, Ali SS, Dao DN, Lucero J, Shekhtman G, Quick KL, Dugan LL (2007) Ketamine-induced loss of phenotype of fast-spiking interneurons is mediated by NADPH-oxidase. Science 318:1645-1647.

Belforte JE, Zsiros V, Sklar ER, Jiang Z, Yu G, Li Y, Quinlan EM, Nakazawa K (2010) Postnatal NMDA receptor ablation in corticolimbic interneurons confers schizophrenia-like phenotypes. Nat Neurosci 13:76-83.

Benson DL, Huntsman MM, Jones EG (1994) Activity-dependent changes in GAD and preprotachykinin mRNAs in visual cortex of adult monkeys. Cereb Cortex 4:40-51.

Berger TK, Perin R, Silberberg G, Markram H (2009) Frequency-dependent disynaptic inhibition in the pyramidal network: a ubiquitous pathway in the developing rat neocortex. J Physiol 587:5411-5425.

Biró AA, Nusser Z (2005) Synapse independence breaks down during highly synchronous network activity in the rat hippocampus. Eur J Neurosci 22:1257-1262.

Bitanihirwe BK, Lim MP, Kelley JF, Kaneko T, Woo TU (2009) Glutamatergic deficits and parvalbumin-containing inhibitory neurons in the prefrontal cortex in schizophrenia. BMC Psychiatry 9:71.

Buhl EH, Tamás G, Fisahn A (1998) Cholinergic activation and tonic excitation induce persistent gamma oscillations in mouse somatosensory cortex in vitro. J Physiol 513:117-126.

Cardin JA, Carlén M, Meletis K, Knoblich U, Zhang F, Deisseroth K, Tsai LH, Moore CI (2009) Driving fast-spiking cells induces gamma rhythm and controls sensory responses. Nature 459:663-667.

Chattopadhyaya B, Di Cristo G, Higashiyama H, Knott GW, Kuhlman SJ, Welker E, Huang ZJ (2004) Experience and activity-dependent maturation of perisomatic GABAergic innervation in primary visual cortex during a postnatal critical period. J Neurosci 24:9598-9611.

Chen X, Shu S, Bayliss DA (2009) HCN1 channel subunits are a molecular substrate for hypnotic actions of ketamine. J Neurosci 29:600-609.

Cho RY, Konecky RO, Carter CS (2006) Impairments in frontal cortical gamma synchrony and cognitive control in schizophrenia. Proc Natl Acad Sci U S A 103:19878-19883.

Cochran SM, Kennedy M, McKerchar CE, Steward LJ, Pratt JA, Morris BJ (2003) Induction of metabolic hypofunction and neurochemical deficits 
after chronic intermittent exposure to phencyclidine: differential modulation by antipsychotic drugs. Neuropsychopharmacology 28:265-275.

Coyle JT (2004) The GABA-glutamate connection in schizophrenia: which is the proximate cause? Biochem Pharmacol 68:1507-1514.

Cull-Candy SG, Leszkiewicz DN (2004) Role of distinct NMDA receptor subtypes at central synapses. Sci STKE 2004:re16.

Cunningham MO, Hunt J, Middleton S, LeBeau FE, Gillies MJ, Davies CH, Maycox PR, Whittington MA, Racca C (2006) Region-specific reduction in entorhinal gamma oscillations and parvalbumin-immunoreactive neurons in animal models of psychiatric illness. J Neurosci 26:2767-2776.

Dingledine R, Borges K, Bowie D, Traynelis SF (1999) The glutamate receptor ion channels. Pharmacol Rev 51:7-61.

Doischer D, Hosp JA, Yanagawa Y, Obata K, Jonas P, Vida I, Bartos M (2008) Postnatal differentiation of basket cells from slow to fast signaling devices. J Neurosci 28:12956-12968.

Esclapez M, Houser CR (1999) Up-regulation of GAD65 and GAD67 in remaining hippocampal GABA neurons in a model of temporal lobe epilepsy. J Comp Neurol 412:488-505.

Fellous JM, Sejnowski TJ (2003) Regulation of persistent activity by background inhibition in an in vitro model of a cortical microcircuit. Cereb Cortex 13:1232-1241.

Fisahn A, Pike FG, Buhl EH, Paulsen O (1998) Cholinergic induction of network oscillations at $40 \mathrm{~Hz}$ in the hippocampus in vitro. Nature 394:186-189.

Forsythe ID, Westbrook GL, Mayer ML (1988) Modulation of excitatory synaptic transmission by glycine and zinc in cultures of mouse hippocampal neurons. J Neurosci 8:3733-3741.

Fricker D, Miles R (2000) EPSP amplification and the precision of spike timing in hippocampal neurons. Neuron 28:559-569.

Fries P (2009) Neuronal gamma-band synchronization as a fundamental process in cortical computation. Annu Rev Neurosci 32:209-224.

Fuchs EC, Zivkovic AR, Cunningham MO, Middleton S, LeBeau FE, Bannerman DM, Rozov A, Whittington MA, Traub RD, Rawlins JN, Monyer H (2007) Recruitment of parvalbumin-positive interneurons determines hippocampal function and associated behavior 14. Neuron 53:591-604.

Galarreta M, Hestrin S (2001) Spike transmission and synchrony detection in networks of GABAergic interneurons. Science 292:2295-2299.

Galarreta M, Hestrin S (2002) Electrical and chemical synapses among parvalbumin fast-spiking GABAergic interneurons in adult mouse neocortex. Proc Natl Acad Sci U S A 99:12438-12443.

Geiger JR, Melcher T, Koh DS, Sakmann B, Seeburg PH, Jonas P, Monyer H (1995) Relative abundance of subunit mRNAs determines gating and $\mathrm{Ca} 2+$ permeability of AMPA receptors in principal neurons and interneurons in rat CNS. Neuron 15:193-204.

Geiger JR, Lübke J, Roth A, Frotscher M, Jonas P (1997) Submillisecond AMPA receptor-mediated signaling at a principal neuron-interneuron synapse. Neuron 18:1009-1023.

Gentet LJ, Avermann M, Matyas F, Staiger JF, Petersen CC (2010) Membrane potential dynamics of GABAergic neurons in the barrel cortex of behaving mice. Neuron 65:422-435.

Gittis AH, Nelson AB, Thwin MT, Palop JJ, Kreitzer AC (2010) Distinct roles of GABAergic interneurons in the regulation of striatal output pathways. J Neurosci 30:2223-2234.

Goldberg JH, Tamas G, Aronov D, Yuste R (2003) Calcium microdomains in aspiny dendrites. Neuron 40:807-821.

González-Burgos G, Barrionuevo G (2001) Voltage-gated sodium channels shape subthreshold EPSPs in layer 5 pyramidal neurons from rat prefrontal cortex. J Neurophysiol 86:1671-1684.

Gonzalez-Burgos G, Lewis DA (2008) GABA neurons and the mechanisms of network oscillations: implications for understanding cortical dysfunction in schizophrenia. Schizophr Bull 34:944-961.

Grunze HC, Rainnie DG, Hasselmo ME, Barkai E, Hearn EF, McCarley RW, Greene RW (1996) NMDA-dependent modulation of CA1 local circuit inhibition. J Neurosci 16:2034-2043.

Hájos N, Paulsen O (2009) Network mechanisms of gamma oscillations in the CA3 region of the hippocampus. Neural Netw 22:1113-1119.

Hakami T, Jones NC, Tolmacheva EA, Gaudias J, Chaumont J, Salzberg M, O’Brien TJ, Pinault D (2009) NMDA receptor hypofunction leads to generalized and persistent aberrant gamma oscillations independent of hyperlocomotion and the state of consciousness. PLoS One 4:e6755.

Hasenstaub A, Shu Y, Haider B, Kraushaar U, Duque A, McCormick DA
(2005) Inhibitory postsynaptic potentials carry synchronized frequency information in active cortical networks. Neuron 47:423-435.

He HY, Hodos W, Quinlan EM (2006) Visual deprivation reactivates rapid ocular dominance plasticity in adult visual cortex. J Neurosci 26:29512955.

Hestrin S, Nicoll RA, Perkel DJ, Sah P (1990) Analysis of excitatory synaptic action in pyramidal cells using whole-cell recording from rat hippocampal slices. J Physiology 422:203-225.

Homayoun H, Moghaddam B (2007) NMDA receptor hypofunction produces opposite effects on prefrontal cortex interneurons and pyramidal neurons. J Neurosci 27:11496-11500.

Hong LE, Summerfelt A, Buchanan RW, O’Donnell P, Thaker GK, Weiler MA, Lahti AC (2010) Gamma and delta neural oscillations and association with clinical symptoms under subanesthetic ketamine. Neuropsychopharmacology 35:632-640.

Hu H, Martina M, Jonas P (2010) Dendritic mechanisms underlying rapid synaptic activation of fast-spiking hippocampal interneurons. Science 327:52-58.

Huettner JE, Bean BP (1988) Block of N-methyl-D-aspartate-activated current by the anticonvulsant MK-801: selective binding to open channels. Proc Natl Acad Sci U S A 85:1307-1311.

Hull C, Isaacson JS, Scanziani M (2009) Postsynaptic mechanisms govern the differential excitation of cortical neurons by thalamic inputs. J Neurosci 29:9127-9136.

Izhikevich EM (2004) Which model to use for cortical spiking neurons? IEEE Trans Neural Netw 15:1063-1070.

Javitt DC (2009) When doors of perception close: bottom-up models of disrupted cognition in schizophrenia. Annu Rev Clin Psychol 5:249-275.

Javitt DC, Zukin SR (1991) Recent advances in the phencyclidine model of schizophrenia. Am J Psychiatry 148:1301-1308.

Jiao Y, Zhang C, Yanagawa Y, Sun QQ (2006) Major effects of sensory experiences on the neocortical inhibitory circuits. J Neurosci 26:8691-8701.

Jodo E, Suzuki Y, Katayama T, Hoshino KY, Takeuchi S, Niwa S, Kayama Y (2005) Activation of medial prefrontal cortex by phencyclidine is mediated via a hippocampo-prefrontal pathway. Cereb Cortex 15:663-669.

Jonas P, Bischofberger J, Fricker D, Miles R (2004) Interneuron diversity series: fast in, fast out-temporal and spatial signal processing in hippocampal interneurons. Trends Neurosci 27:30-40.

Jones EG (1990) The role of afferent activity in the maintenance of primate neocorticalfunction. J Exp Biol 153:155-176.

Jones KA, Baughman RW (1988) NMDA- and non-NMDA-receptor components of excitatory synaptic potentials recorded from cells in layer $\mathrm{V}$ of rat visual cortex. J Neurosci 8:3522-3534.

Kapfer C, Glickfeld LL, Atallah BV, Scanziani M (2007) Supralinear increase of recurrent inhibition during sparse activity in the somatosensory cortex. Nat Neurosci 10:743-753.

Karayannis T, Huerta-Ocampo I, Capogna M (2007) GABAergic and pyramidal neurons of deep cortical layers directly receive and differently integrate callosal input. Cereb Cortex 17:1213-1226.

Kargieman L, Santana N, Mengod G, Celada P, Artigas F (2007) Antipsychotic drugs reverse the disruption in prefrontal cortex function produced by NMDA receptor blockade with phencyclidine. Proc Natl Acad Sci U S A 104:14843-14848.

Kawaguchi Y, Kubota Y (1997) GABAergic cell subtypes and their synaptic connections in rat frontal cortex. Cereb Cortex 7:476-486.

Kinney JW, Davis CN, Tabarean I, Conti B, Bartfai T, Behrens MM (2006) A specific role for NR2A-containing NMDA receptors in the maintenance of parvalbumin and GAD67 immunoreactivity in cultured interneurons. J Neurosci 26:1604-1615.

Kole MH, Hallermann S, Stuart GJ (2006) Single $I_{\mathrm{h}}$ channels in pyramidal neuron dendrites: properties, distribution, and impact on action potential output. J Neurosci 26:1677-1687.

Kristiansen LV, Huerta I, Beneyto M, Meador-Woodruff JH (2007) NMDA receptors and schizophrenia. Curr Opin Pharmacol 7:48-55.

Kroener S, Chandler LJ, Phillips PE, Seamans JK (2009) Dopamine modulates persistent synaptic activity and enhances the signal-to-noise ratio in the prefrontal cortex. PLoS One 4:e6507.

Lamsa KP, Heeroma JH, Somogyi P, Rusakov DA, Kullmann DM (2007) Anti-Hebbian long-term potentiation in the hippocampal feedback inhibitory circuit. Science 315:1262-1266.

Larkum ME, Nevian T, Sandler M, Polsky A, Schiller J (2009) Synaptic in- 
tegration in tuft dendrites of layer 5 pyramidal neurons: a new unifying principle. Science 325:756-760.

LeBeau FE, Towers SK, Traub RD, Whittington MA, Buhl EH (2002) Fast network oscillations induced by potassium transients in the rat hippocampus in vitro. J Physiol 542:167-179.

Lewis BL, O'Donnell P (2000) Ventral tegmental area afferents to the prefrontal cortex maintain membrane potential 'up' states in pyramidal neurons via $\mathrm{D}(1)$ dopamine receptors. Cereb Cortex 10:1168-1175.

Lewis DA, Moghaddam B (2006) Cognitive dysfunction in schizophrenia: convergence of gamma-aminobutyric acid and glutamate alterations. Arch Neurol 63:1372-1376.

Lewis DA, Hashimoto T, Volk DW (2005) Cortical inhibitory neurons and schizophrenia. Nat Rev Neurosci 6:312-324.

Liang F, Jones EG (1997) Differential and time-dependent changes in gene expression for type II calcium/calmodulin-dependent protein kinase, 67 $\mathrm{kDa}$ glutamic acid decarboxylase, and glutamate receptor subunits in tetanus toxin-induced focal epilepsy. J Neurosci 17:2168-2180.

Ling DS, Benardo LS (1995) Recruitment of GABAA inhibition in rat neocortex is limited and not NMDA dependent. J Neurophysiol 74:2329-2335.

Lisman JE, Fellous JM, Wang XJ (1998) A role for NMDA-receptor channels in working memory. Nat Neurosci 1:273-275.

Lisman JE, Coyle JT, Green RW, Javitt DC, Benes FM, Heckers S, Grace AA (2008) Circuit-based framework for understanding neurotransmitter and risk gene interactions in schizophrenia. Trends Neurosci 31:234-242.

Lu JT, Li CY, Zhao JP, Poo MM, Zhang XH (2007) Spike-timing-dependent plasticity of neocortical excitatory synapses on inhibitory interneurons depends on target cell type. J Neurosci 27:9711-9720.

Maccaferri G, Dingledine R (2002) Control of feedforward dendritic inhibition by NMDA receptor-dependent spike timing in hippocampal interneurons. J Neurosci 22:5462-5472.

Magee JC (1998) Dendritic hyperpolarization-activated currents modify the integrative properties of hippocampal CA1 pyramidal neurons. J Neurosci 18:7613-7624.

Mann EO, Paulsen O (2007) Role of GABAergic inhibition in hippocampal network oscillations. Trends Neurosci 30:343-349.

Mann EO, Radcliffe CA, Paulsen O (2005a) Hippocampal gamma-frequency oscillations: from interneurones to pyramidal cells, and back. J Physiol 562:55-63.

Mann EO, Suckling JM, Hajos N, Greenfield SA, Paulsen O (2005b) Perisomatic feedback inhibition underlies cholinergically induced fast network oscillations in the rat hippocampus in vitro. Neuron 45:105-117.

Markram H, Lubke J, Frotscher M, Roth A, Sakmann B (1997) Physiology and anatomy of synaptic connections between thick tufted pyramidal neurones in the developing rat neocortex. J Physiology 500:409-440.

Markram H, Toledo-Rodriguez M, Wang Y, Gupta A, Silberberg G, Wu C (2004) Interneurons of the neocortical inhibitory system. Nat Rev Neurosci 5:793-807.

McCormick DA, Shu Y, Hasenstaub A, Sanchez-Vives M, Badoual M, Bal T (2003) Persistent cortical activity: mechanisms of generation and effects on neuronal excitability. Cereb Cortex 13:1219-1231.

Nissen W, Szabo A, Somogyi J, Somogyi P, Lamsa KP (2010) Cell typespecific long-term plasticity at glutamatergic synapses onto hippocampal interneurons expressing either parvalbumin or CB1 cannabinoid receptor. J Neurosci 30:1337-1347.

Nyíri G, Stephenson FA, Freund TF, Somogyi P (2003) Large variability in synaptic N-methyl-D-aspartate receptor density on interneurons and a comparison with pyramidal-cell spines in the rat hippocampus. Neuroscience 119:347-363.

Oren I, Mann EO, Paulsen O, Hájos N (2006) Synaptic currents in anatomically identified CA3 neurons during hippocampal gamma oscillations in vitro. J Neurosci 26:9923-9934.

Pawelzik H, Hughes DI, Thomson AM (2002) Physiological and morphological diversity of immunocytochemically defined parvalbumin- and cholecystokinin-positive interneurones in CA1 of the adult rat hippocampus. J Comp Neurol 443:346-367.

Pietersen AN, Patel N, Jefferys JG, Vreugdenhil M (2009) Comparison between spontaneous and kainate-induced gamma oscillations in the mouse hippocampus in vitro. Eur J Neurosci 29:2145-2156.

Pinault D (2008) N-methyl d-aspartate receptor antagonists ketamine and MK-801 induce wake-related aberrant gamma oscillations in the rat neocortex. Biol Psychiatry 63:730-735.
Pirot S, Godbout R, Mantz J, Tassin JP, Glowinski J, Thierry AM (1992) Inhibitory effects of ventral tegmental area stimulation on the activity of prefrontal cortical neurons: evidence for the involvement of both dopaminergic and GABAergic components. Neuroscience 49:857-865.

Potez S, Larkum ME (2008) Effect of common anesthetics on dendritic properties in layer 5 neocortical pyramidal neurons. J Neurophysiol 99:1394-1407.

Pouille F, Marin-Burgin A, Adesnik H, Atallah BV, Scanziani M (2009) Input normalization by global feedforward inhibition expands cortical dynamic range. Nat Neurosci 12:1577-1585.

Povysheva NV, Zaitsev AV, Rotaru DC, Gonzalez-Burgos G, Lewis DA, Krimer LS (2008) Parvalbumin-positive basket interneurons in monkey and rat prefrontal cortex. J Neurophysiol 100:2348-2360.

Puig MV, Ushimaru M, Kawaguchi Y (2008) Cell type-specific control of neuronal responsiveness by gamma-band oscillatory inhibition. Proc Natl Acad Sci U S A 105:8428-8433.

Roopun AK, Cunningham MO, Racca C, Alter K, Traub RD, Whittington MA (2008) Region-specific changes in gamma and beta2 rhythms in NMDA receptor dysfunction models of schizophrenia. Schizophr Bull 34:962-973.

Rotaru DC, Lewis DA, Gonzalez-Burgos G (2007) Dopamine D1 receptor activation regulates sodium channel-dependent EPSP amplification in rat prefrontal cortex pyramidal neurons. J Physiol 581:981-1000.

Sambandan S, Sauer JF, Vida I, Bartos M (2010) Associative plasticity at excitatory synapses facilitates recruitment of fast-spiking interneurons in the dentate gyrus. J Neurosci 30:11826-11837.

Schiller J, Major G, Koester HJ, Schiller Y (2000) NMDA spikes in basal dendrites of cortical pyramidal neurons. Nature 404:285-289.

Seamans JK, Nogueira L, Lavin A (2003) Synaptic basis of persistent activity in prefrontal cortex in vivo and in organotypic cultures. Cereb Cortex 13:1242-1250.

Silberberg G, Markram H (2007) Disynaptic inhibition between neocortical pyramidal cells mediated by Martinotti cells. Neuron 53:735-746.

Sohal VS, Zhang F, Yizhar O, Deisseroth K (2009) Parvalbumin neurons and gamma rhythms enhance cortical circuit performance. Nature 459:698-702.

Steriade M, Nuñez A, Amzica F (1993) A novel slow ( $<1 \mathrm{~Hz}$ ) oscillation of neocortical neurons in vivo: depolarizing and hyperpolarizing components. J Neurosci 13:3252-3265.

Stuart G, Sakmann B (1995) Amplification of EPSPs by axosomatic sodium channels in neocortical pyramidal neurons. Neuron 15:1065-1076.

Suzuki Y, Jodo E, Takeuchi S, Niwa S, Kayama Y (2002) Acute administration of phencyclidine induces tonic activation of medial prefrontal cortex neurons in freely moving rats. Neuroscience 114:769-779.

Thomson AM (1986) A magnesium-sensitive post-synaptic potential in rat cerebral cortex resembles neuronal responses to N-methylaspartate. J Physiol 370:531-549.

Thomson AM (1997) Activity-dependent properties of synaptic transmission at two classes of connections made by rat neocortical pyramidal axons in vitro. J Physiol 502:131-147.

Thomson AM, West DC (1986) N-methylaspartate receptors mediate epileptiform activity evoked in some, but not all, conditions in rat neocortical slices. Neuroscience 19:1161-1177.

Thomson AM, Girdlestone D, West DC (1988) Voltage-dependent currents prolong single-axon postsynaptic potentials in layer III pyramidal neurons in rat neocortical slices. J Neurophysiol 60:1896-1907.

Traub RD, Whittington MA, Colling SB, Buzsáki G, Jefferys JG (1996) Analysis of gamma rhythms in the rat hippocampus in vitro and in vivo. J Physiol 493:471-484.

Tseng KY, Mallet N, Toreson KL, Le Moine C, Gonon F, O’Donnell P (2006) Excitatory response of prefrontal cortical fast-spiking interneurons to ventral tegmental area stimulation in vivo. Synapse 59:412-417.

Tu Y, Kroener S, Abernathy K, Lapish C, Seamans J, Chandler LJ, Woodward JJ (2007) Ethanol inhibits persistent activity in prefrontal cortical neurons. J Neurosci 27:4765-4775.

Vreugdenhil M, Jefferys JG, Celio MR, Schwaller B (2003) Parvalbumindeficiency facilitates repetitive IPSCs and gamma oscillations in the hippocampus. J Neurophysiol 89:1414-1422.

Waites CL, Craig AM, Garner CC (2005) Mechanisms of vertebrate synaptogenesis. Annu Rev Neurosci 28:251-274. 
Wang H, Stradtman GG 3rd, Wang XJ, Gao WJ (2008) A specialized NMDA receptor function in layer 5 recurrent microcircuitry of the adult rat prefrontal cortex. Proc Natl Acad Sci U S A 105:16791-16796.

Wang HX, Gao WJ (2009) Cell type-specific development of NMDA receptors in the interneurons of rat prefrontal cortex. Neuropsychopharmacology 34:2028-2040.

Wang HX, Gao WJ (2010) Development of calcium-permeable AMPA receptors and their correlation with NMDA receptors in fast-spiking interneurons of rat prefrontal cortex. J Physiol 588:2823-2838.

Wang XJ (1999) Synaptic basis of cortical persistent activity: the importance of NMDA receptors to working memory. J Neurosci 19:9587-9603.

Watanabe J, Rozov A, Wollmuth LP (2005) Target-specific regulation of synaptic amplitudes in the neocortex. J Neurosci 25:1024-1033.

Waters J, Helmchen F (2006) Background synaptic activity is sparse in neocortex. J Neurosci 26:8267-8277.
Whittington MA, Traub RD, Kopell N, Ermentrout B, Buhl EH (2000) Inhibition-based rhythms: experimental and mathematical observations on network dynamics. Int J Psychophysiol 38:315-336.

Zaitsev AV, Gonzalez-Burgos G, Povysheva NV, Kröner S, Lewis DA, Krimer LS (2005) Localization of calcium-binding proteins in physiologically and morphologically characterized interneurons of monkey dorsolateral prefrontal cortex. Cereb Cortex 15:1178-1186.

Zaitsev AV, Povysheva NV, Gonzalez-Burgos G, Rotaru D, Fish KN, Krimer LS, Lewis DA (2009) Interneuron diversity in layers 2-3 of monkey prefrontal cortex. Cereb Cortex 19:1597-1615.

Zweifel LS, Parker JG, Lobb CJ, Rainwater A, Wall VZ, Fadok JP, Darvas M, Kim MJ, Mizumori SJ, Paladini CA, Phillips PE, Palmiter RD (2009) Disruption of NMDAR-dependent burst firing by dopamine neurons provides selective assessment of phasic dopamine-dependent behavior. Proc Natl Acad Sci U S A 106:7281-7288. 